\title{
Antecedents and consequences of virtual customer co-creation behaviours
}

\author{
Marta Frasquet-Deltoro \\ Department of Marketing, Universidad de Valencia, Valencia, Spain \\ María-del-Carmen Alarcón-del-Amo \\ Department of Marketing, University of Murcia, Murcia, Spain, and \\ Carlota Lorenzo-Romero \\ Department of Marketing, Faculty of Economics and Business, \\ University of Castilla-la Mancha, Albacete, Spain
}

\begin{abstract}
Purpose - The purpose of this paper is to compare the antecedents and consequences of two distinct types of virtual co-creation behaviours that require different degree of effort from the customer, i.e. customer participation (CPB), and customer citizenship (CCB) behaviour, in a cross-cultural study.

Design/methodology/approach - A survey was conducted among members of online panels in the UK and Spain, reaching a sample of 800 online individuals who participate in online co-creation processes with fashion retailers. This design allows us to test the cross-cultural effects. Multi-group structural equations modelling was used to analyse the data.

Findings - Virtual co-creation behaviours are driven by perceived ease-of-use of the co-creation platform, electronic word-of-mouth (e-WOM) quality and fashion involvement; however, the effects are different on $\mathrm{CPB}$, affected by perceived ease-of-use more strongly, and on $\mathrm{CCB}$, driven by e-WOM quality and fashion involvement more strongly. Higher level of co-creation increases satisfaction with co-creation, which mediates the effect on engagement and intention of future co-creation. The cross-cultural design reveals that most relationships hold in both countries, with the exception of the influence of fashion involvement on $\mathrm{CPB}$, while some differences in the size of the effects appear between countries.

Originality/value - This study contributes to increasing our knowledge on online co-creation in several ways. First, the authors investigate, in the online environment, two co-creation behaviours, $\mathrm{CPB}$ and CCB, and compare their antecedents. This paper provides a cross-cultural validation of the relationships between $\mathrm{CPB}$ and CCB's antecedents and consequences, identifying the different effects due to culture.
\end{abstract}

Keywords Participation, Involvement, Cross-cultural, Customer citizenship behaviour, e-WOM quality, Online co-creation

Paper type Research paper

\section{Introduction}

The view of customers as co-creators of value is a central idea in the service-dominant logic of marketing, which challenges the view of consumers as passive buyers to see them as actors in the production of personalised offers (Payne et al., 2009; Prahalad and Ramaswamy, 2004; Vargo and Lusch, 2004). The increased digitalization of the economy and the adoption of omnichannel strategies by firms (Verhoef et al., 2015) empower consumers and enable mass and multifaceted co-creation (Zhang et al., 2017; Zwass, 2010). Customer co-creation behaviours are easier to perform online than offline and are particularly stimulated through the use of social network sites (SNS) (Wu et al., 2017). Consequently, firms are investing considerable resources in developing online engagement platforms that allow high levels of interactivity with customers and create brand equity, for example, the interactive NikeID platform which allows customers to co-design their shoes (Ramaswamy and Ozcan, 2016). This has motivated a growing research interest to understand online consumer behaviour and the reasons why people interact with each other and with brands in SNS (Hong-Youl et al., 2016; Ortiz et al., 2017). 
Although it is believed that customer co-creation contributes to firms' results as it establishes stronger relationships and increases engagement (Prahalad and Ramaswamy, 2004), the benefits of organising and motivating consumers to co-create are not yet fully understood (France et al., 2015). Initial research focussed on productivity gains by the customers acting as partial employees (Lovelock and Young, 1979); however, Bendapudi and Leone (2003) claimed that further investigation is necessary to uncover customers' psychological responses to co-creation. Some evidence relates co-creation with approach behaviours towards the firm, for instance loyalty (Grissemann and Stokburger-Sauer, 2012; Cossío-Silva et al., 2016). In order to stimulate co-creation behaviours, firms need to understand what drives customers to co-create; however, there is a scarcity of research on the antecedents of co-creation, particularly in the online context (France et al., 2015). In the offline context, Bettencourt (1997) suggested that customers are more willing to co-create when they are committed to the firm and feel supported; while in the online context, Anaza and Zhao (2013) and Wu et al. (2017) suggest that co-creation depends on the quality of the customer-firm relationship.

Bendapudi and Leone (2003) suggest that the implications of co-creation differ depending on whether the customer is forced to participate (e.g. having to use self-checkout) or is given the option to co-create (e.g. the possibility of customising a product). Our research focusses on the second case, i.e. consumer voluntary behaviours (Wu et al., 2017). This corresponds with the definition of France et al. (2015, p. 852): "Customer brand co-creation behaviours are the customer-led interactions between the customer and the brand", which suggests that it is the customer's choice to participate. Within customer voluntary co-creation behaviours, the literature has identified customer participation behaviour (CPB) and customer citizenship behaviour (CCB) as two distinct behaviour types (Groth, 2005; Yi and Gong, 2013). CPB are expected behaviours necessary for the service to be delivered or the co-creation to be completed, whereas CCB are richer behaviours that are discretionary and exceed task performance, thus, providing extraordinary value for firms (Groth, 2005). Therefore, while firms are interested in persuading customers to perform $\mathrm{CPB}$ they are especially interested in $\mathrm{CCB}$ due to the richer potential benefits involved. Although there is some evidence that the antecedents of these two types of behaviours follow different patterns (Groth, 2005; Yi et al., 2011), these have not been compared in the online environment. Several studies have analysed the antecedents of CCB in virtual environments (e.g. Anaza, 2014; Anaza and Zhao, 2013; Wu et al., 2017; Zhu et al., 2016) but to the best of our knowledge no studies have investigated co-creation in virtual environments by contemplating $\mathrm{CCB}$ and $\mathrm{CPB}$ simultaneously. Thus, the main contribution of our study is comparing, in the online context, the antecedents and consequences of two types of co-creation behaviour, $\mathrm{CPB}$ and CCB. An additional contribution of this paper is adopting a contingency approach that examines the potential moderating effect of culture. Several authors suggest that culture has far-reaching influences on, for example, the perceived value of websites and consumer innovativeness (e.g. Alden et al., 1999, Steenkamp and Geyskens, 2006; Steenkamp et al., 1999) and customers' preferences for personalised service (Mattila, 1999). Although these aspects are somehow related to online co-creation, the role of culture as moderator of the relationship between online co-creation and its antecedents and consequences, to the best of our knowledge, has not been explored in the literature despite a research call launched by $\mathrm{Yi}$ and Gong (2013).

Therefore, with the aim of increasing the limited knowledge on virtual co-creation, our objectives are: first, to test a comprehensive model that includes simultaneously antecedents and consequences of the virtual co-creation behaviours of $\mathrm{CPB}$ and $\mathrm{CCB}$; second, to assess whether the antecedents have a different effect for the two types of co-creation behaviours; and third, to assess the moderator effect of culture by testing the proposed model in two different countries, Spain and the UK, which differ in the degree of internet and social media 
usage to interact with firms (Eurostat, 2017a). We base our study in the fashion retail sector as this is an interesting context to analyse online co-creation since fashion retailers are heavily investing in digital channels and little research in co-creation has developed in this sector.

This paper is structured as follows. The following section presents the literature review on $\mathrm{CPB}, \mathrm{CCB}$ and online co-creation, and Section 3 discusses the hypotheses. Section 4 reports the methodology of the empirical study. Section 5 presents the results, while the meaning of the results is discussed in Section 6. Finally, Section 7 contains the theoretical and managerial contributions as well as limitations and future research lines.

\section{Literature review}

\subsection{Co-creation behaviours: $C P B$ and $C C B$}

The literature contributing to understanding the role of customer co-creation for firms originates from different research fields, and this explains why different terms are used to refer to the same or closely related concepts (Groth, 2005; Yi et al., 2011). In a recent study, Wu et al. (2017) attempt to clarify the terminology related to consumer voluntary behaviours and as a result they distinguish the following four behaviours: $\mathrm{CPB}, \mathrm{CCB}$, information sharing and prosocial behaviours. Of these, $\mathrm{CPB}$ and $\mathrm{CCB}$ are the behaviours that have been most studied as they both affect the customer and the firm, whereas information sharing or prosocial behaviours merely affect other customers. It is the services marketing literature that has most used the distinction between $\mathrm{CPB}$ and $\mathrm{CCB}$ in the service delivery process (Bove et al., 2009; Groth, 2005; Yi et al., 2011; Yi and Gong, 2013), although often using different terms (e.g. coproduction for $\mathrm{CPB}$ ). The early interest shown in the services marketing literature to investigate the participatory role of customers (Kelley et al., 1990; Bettencourt, 1997) is due to the unique characteristic of services where the customer interacts with the service provider to co-produce the service.

The concepts of $\mathrm{CPB}$ and $\mathrm{CCB}$ have their roots in the organisational behaviour literature, with Podsakoff and MacKenzie (1997) distinguishing in-role vs extra-role behaviours of employees. Following significant interest in the organisational literature (see the literature review by Podsakoff et al., 2014), the distinction was extended to the customer domain by Groth (2005), who defined CPB as "expected and required behaviours necessary for the successful production and/or delivery of the service" and CCB as "voluntary and discretionary behaviours that are not required for the successful production and/or delivery of the service, but that, in the aggregate, help the service organization overall" (p. 11). CPB are necessary for the service to be delivered or the co-creation to be complete and include actions such as sharing information with the firm to understand and complete the task and accepting the duties as value co-creators (Yi and Gong, 2013); for example, in the context of an online cocreation task such as a social media co-design contest, CPB means completing all the personal information required from the firm. As Wu et al. (2017) argue, CPB is good for both the customer and the firm, and thus, can be classified as "for-self" behaviour. In contrast, CCB is "for-others" behaviour as it benefits other customers and the firm. Following the previous example of an online co-design contest, $\mathrm{CCB}$ would imply providing feedback to the firm and suggestions to improve the co-design contest. The literature clarifies that $\mathrm{CCB}$ has to be functional to the organisation; those behaviours that are for others but do not help the firm, such as sharing knowledge with other customers about a competitor having lower prices than the firm, are not classified as CCB (Bove et al., 2009; Wu et al., 2017). CCB means the customer goes "the extra mile" and provides help and assistance to employees or fellow customers (Yi and Gong, 2008). Consequently, the literature highlights the extraordinary value of CCB for organisational performance (Bove et al., 2009), being the most critical CCB behaviour that firms should enhance (Wu et al., 2017). 
In line with the novelty of the concept of customer co-creation and the variety of theoretical approaches towards its study, the dimensionality of $\mathrm{CPB}$ and $\mathrm{CCB}$ has not yet been clearly established. Focussing on $\mathrm{CCB}$, which has been the more researched of the two behaviours, Bettencourt (1997) suggested three dimensions: loyalty (the customer as promoter of the firm), cooperation (the customer as a human resource) and participation (the customer as an organisational consultant). Moreover, Groth (2005), following a scale development process, obtained three dimensions of CCB: recommendations, feedback and helping others. However, some authors, such as Bove et al. (2009) or Wu et al. (2017), do not contemplate multidimensionality. The paper of Yi and Gong (2013) is a serious attempt to establish the dimensionality of both constructs by following a structured approach towards scale development and validation. These authors suggest that CPB has four dimensions: information seeking, information sharing, responsible behaviour and personal interaction, whereas CCB comprises feedback, advocacy, helping and tolerance.

\subsection{Co-creation in the online environment}

Following the opportunities that online channels provide companies in terms of managing online co-creation encounters, interest has developed in investigating the processes of online co-creation. However, the literature is still scarce and fragmented with some conceptual papers that develop frameworks and research propositions (e.g. France et al., 2015; Ramaswamy and Ozcan, 2016; Zwass, 2010) and a few empirical papers that draw on existing theories to develop research models (see Table I). Most empirical papers investigate the antecedents rather than the consequences of online co-creation. Our literature review also reveals that there is significant diversity in the context of the study and in the definition of the variables measuring online co-creation, which in some studies are CCB behaviours, and in other studies are measures of participation or experience.

\section{Research model and hypotheses}

The central constructs of our research model (Figure 1) are the two types of voluntary co-creation behaviours - CPB and CCB - as defined by Groth (2005) and operationalised by Yi and Gong's (2013). Our model is rooted in the logic of the conceptual model of value co-creation in the context of service-dominant logic developed by Payne et al. (2009). This is a comprehensive model that understands value co-creation as the integration of four components: encounters, customer processes, supplier processes and additional sources of brand knowledge. Encounters are "processes where both parties are interacting and mutually co-creating experiences" (Payne et al., 2009, p. 383), which we operationalise in our model as CPB and CCB. Our model simultaneously investigates the antecedents and consequences of these two behaviours as discussed in the following sections.

\subsection{Antecedents of online co-creation behaviours}

We investigate the influence of three antecedent factors of co-creation behaviours: fashion (category) involvement, perceived ease-of-use and electronic word-of-mouth (e-WOM) quality. These three factors are representative of the three components that impact on encounters of value co-creation according to the conceptual model of Payne et al. (2009): customer processes, supplier processes and additional sources of brand knowledge. Fashion involvement is an individual variable - a psychographic trait - that affects customer processes by making the experience of co-creation emotionally appealing. Perceived ease-of-use of the online co-creation platform represents a supplier value-creating process to support the co-creation activity by making it operationally efficient. The third antecedent of co-creation behaviours in our model is e-WOM quality. The model established by 


\begin{tabular}{|c|c|c|c|}
\hline Authors & Objective & Context & Antecedents/consequences \\
\hline $\begin{array}{l}\text { Nambisan and } \\
\text { Baron (2009) }\end{array}$ & $\begin{array}{l}\text { Understand motivations to } \\
\text { co-create in firm-hosted online } \\
\text { forums }\end{array}$ & $\begin{array}{l}\text { Online forums of } \\
\text { Microsoft and IBM }\end{array}$ & $\begin{array}{l}\text { Antecedents of online participation: } \\
\text { cognitive, social integrative, personal } \\
\text { integrative and hedonic benefits }\end{array}$ \\
\hline $\begin{array}{l}\text { Füller et al. } \\
\text { (2009) }\end{array}$ & $\begin{array}{l}\text { Investigate consumer } \\
\text { empowerment through online } \\
\text { co-creation activities }\end{array}$ & $\begin{array}{l}\text { Virtual product } \\
\text { development in } \\
\text { co-creation projects }\end{array}$ & $\begin{array}{l}\text { Antecedents of future participation } \\
\text { intentions Empowerment, enjoyment } \\
\text { and trust }\end{array}$ \\
\hline $\begin{array}{l}\text { Füller et al. } \\
\text { (2011) }\end{array}$ & $\begin{array}{l}\text { Explore the impact of co- } \\
\text { creation experience on } \\
\text { customer contribution }\end{array}$ & $\begin{array}{l}\text { Virtual design } \\
\text { competition of } \\
\text { jewellery Swarosky }\end{array}$ & $\begin{array}{l}\text { Antecedents of co-creation } \\
\text { experience: sense of community; } \\
\text { consequences: quality of } \\
\text { contributions, amount of } \\
\text { contributions, number of visits and } \\
\text { participation intentions }\end{array}$ \\
\hline $\begin{array}{l}\text { Anaza and } \\
\text { Zhao (2013) }\end{array}$ & $\begin{array}{l}\text { Explore encounter-based } \\
\text { antecedents of CCB }\end{array}$ & $\begin{array}{l}\text { Onlin } \\
\text { shopp }\end{array}$ & $\begin{array}{l}\text { Antecedents of three CCB: } \\
\text { facilitating conditions, e-store } \\
\text { familiarity, satisfaction with firm, } \\
\text { commitment to firm, loyalty to firm }\end{array}$ \\
\hline $\begin{array}{l}\text { Gebauer et al. } \\
\text { (2013) }\end{array}$ & $\begin{array}{l}\text { Explore positive and negative } \\
\text { reactions of participation in } \\
\text { online innovation communities }\end{array}$ & $\begin{array}{l}\text { Online design } \\
\text { contest of retailer } \\
\text { SPAR }\end{array}$ & $\begin{array}{l}\text { Consequences of positive co-creation } \\
\text { experience: WOM, willingness to } \\
\text { pay, sense of community }\end{array}$ \\
\hline Anaza (2014) & $\begin{array}{l}\text { Examine psychological } \\
\text { processes predicting } \mathrm{CCB}\end{array}$ & $\begin{array}{l}\text { Online retail } \\
\text { shopping }\end{array}$ & $\begin{array}{l}\text { Antecedents of three CCB: empathic } \\
\text { concerns and satisfaction with firm }\end{array}$ \\
\hline $\begin{array}{l}\text { Blasco-Arcas } \\
\text { et al. (2014) }\end{array}$ & $\begin{array}{l}\text { Analyse the role of } \\
\text { personalisation and } \\
\text { interactivity in online purchase }\end{array}$ & $\begin{array}{l}\text { Purchase of } \\
\text { services for internet } \\
\text { TV }\end{array}$ & $\begin{array}{l}\text { Antecedents of participation and } \\
\text { future participation intentions: } \\
\text { interactivity, and personalisation }\end{array}$ \\
\hline Blasco (2014) & $\begin{array}{l}\text { Analyse online purchase as a } \\
\text { context to co-create experience }\end{array}$ & $\begin{array}{l}\text { Coproduction in } \\
\text { buying online } \\
\text { customised } \\
\text { products }\end{array}$ & $\begin{array}{l}\text { Antecedents of co-creation } \\
\text { experience: coproduction, C2C } \\
\text { interactions; consequences: purchase } \\
\text { intention }\end{array}$ \\
\hline $\begin{array}{l}\text { Constantinides } \\
\text { et al. }(2015)\end{array}$ & $\begin{array}{l}\text { Understand the motivations } \\
\text { to participate in online } \\
\text { co-creation }\end{array}$ & $\begin{array}{l}\text { New product } \\
\text { development task in } \\
\text { online co-creation }\end{array}$ & $\begin{array}{l}\text { Antecedents of participation: } \\
\text { learning, social integrative, personal } \\
\text { integrative and hedonic benefits }\end{array}$ \\
\hline Zhu et al. (2016) & $\begin{array}{l}\text { Investigate the influence of } \\
\text { social support on CCB through } \\
\text { satisfaction }\end{array}$ & $\begin{array}{l}\text { Online brand } \\
\text { communities of } \\
\text { electronic product } \\
\text { providers }\end{array}$ & $\begin{array}{l}\text { Antecedents of three CCB } \\
\text { behaviours: informational support, } \\
\text { social support and satisfaction with } \\
\text { firm }\end{array}$ \\
\hline Wu et al. (2017) & $\begin{array}{l}\text { Examine how firm level factors } \\
\text { and individual factors affect } \\
\text { CCB in social networks }\end{array}$ & $\begin{array}{l}\text { Facebook social } \\
\text { network of } 7 \text { Eleven } \\
\text { and Starbucks }\end{array}$ & $\begin{array}{l}\text { Antecedents of CCB: identification } \\
\text { with SNS, SNS relationship quality }\end{array}$ \\
\hline
\end{tabular}

Payne et al. (2009) explicitly includes customer-to-customer interaction as an additional source of brand knowledge that may drive customers to actively co-creating.

The relationship between category involvement and customer co-creation has not been evidenced yet but is a research proposition of France et al. (2015), who suggest that for co-creation to occur customers must have a sufficient level of involvement in the specific category of the brand. Involvement is a motivational variable reflecting the extent to which an activity is personally relevant to the individual (Zaichkowsky, 1994). In the organisational literature, a positive relationship has been demonstrated between job involvement and OCB (Dimitriades, 2007). Fashion involvement is the extent to which fashion is considered a central, meaningful and enduring part of an individual's life (O'Cass, 2004); it is an intrinsic motivation that refers to an individual's enjoyment of thinking about and using the products in the category (France et al., 2015). Payne et al. (2009) suggest that those customers that share values and concerns related to a specific task would be more willing to co-create; by co-creating, customers embed themselves in the process of learning 


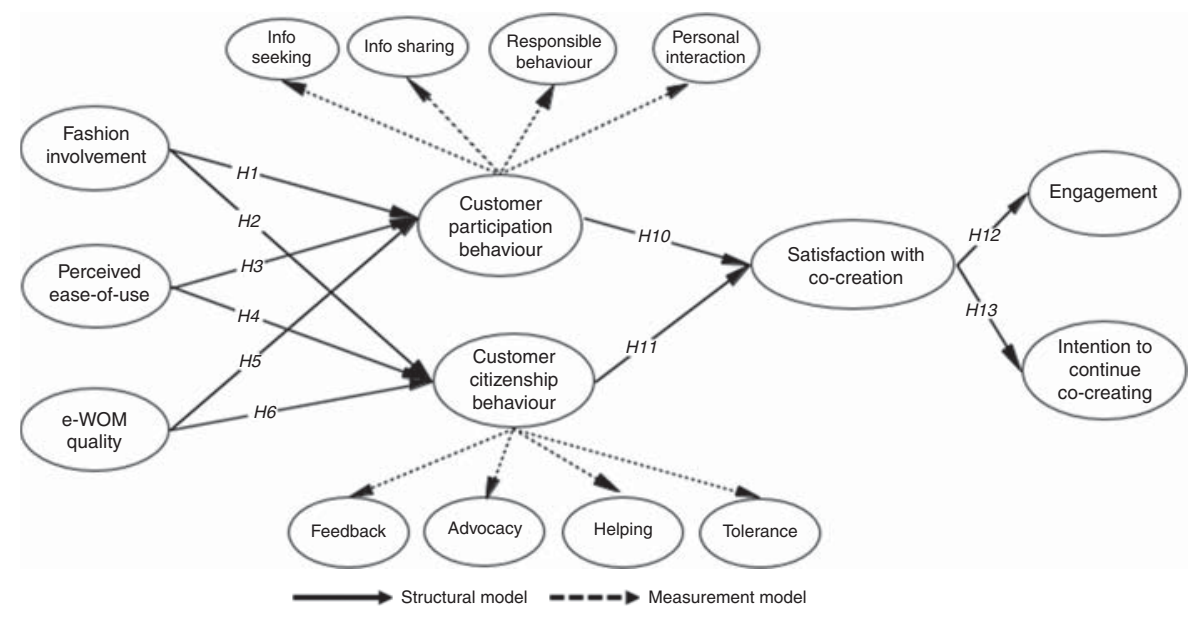

Figure 1. Research model

about the product category. The benefits of online co-creation include learning benefits, which refer to gaining a better understanding and knowledge about the products (Constantinides et al., 2015), and this could be a strong motivation for consumers involved in the product category. As Nambisan and Baron (2009) state, the more important the product is to a customer, the more he or she has a stake in the co-creation task and, therefore, the more likely he or she is to participate in online co-creation. From a list of potential motivators to co-create in virtual words, Zwass (2010) identifies passion for a task and learning through co-creation from and with others; these are attributes that belong to the concept of involvement in the product category. Consumers who are involved in the product category often possess greater knowledge and skills and act as innovators and opinion leaders (Bloch, 1986). Highly involved customers would feel sufficiently competent to engage in virtual co-creation activities and feel that their unique knowledge and insights make a difference (Füller et al., 2009). Thus, we can expect that highly involved customers will be likely to undertake online co-creation:

H1. Fashion involvement positively affects CPB.

H2. Fashion involvement positively affects CCB.

The perceived expertise of the customer, or their self-efficacy related to the task, will also affect the intention to co-create or the actual co-creation behaviour (Bendapudi and Leone, 2003; Xie et al., 2008). In online co-creation processes, customers have to learn to participate through an online platform. The perceived ease-of-use of a technological system is a variable drawn from the technology acceptance model - TAM (Davis, 1989), which has been widely employed as an antecedent of the usage of a technology for performing a task. It is defined as "the degree to which a person believes that using a particular system would be free of effort" (Davis, 1989, p. 320), which in our context applies to the degree to which the customer believes using an online platform for co-creation is free of effort. The impact of perceived ease-of-use for online shopping has been widely investigated (e.g. Gefen et al., 2003; Rose et al., 2012). However, while the widespread use of the internet for searching information and for purchasing has contributed to customers' perception of higher perceived ease-of-use, this is not the case for the co-creation task. Groth (2005) points out that socialisation and training of customers to complete the co-creation task is necessary because many consumers are unfamiliar with virtual co-creation. Higher perceived ease-of-use of the internet for 
co-creation will act as an intrinsic motivation to participate as it will reduce the barriers to perform the task. In the context of a students' discussion forum, Phang et al. (2009) found that participation in the online community increased due to perceived system usability and in particular the perceived ease-of-use of the platform. Similarly, Cano-Murillo et al. (2016) found that perceived ease-of-use of the internet positively affects online prosocial behaviour. Thus, we expect that in the virtual co-creation context perceived ease-of-use would have a positive effect on $\mathrm{CPB}$ and $\mathrm{CCB}$ behaviours:

\section{H3. Perceived ease-of-use of the co-creation platform positively affects CPB.}

H4. Perceived ease-of-use of the co-creation platform positively affects CCB.

The growth in the use of the internet and virtual social media has changed the way people interact with each other. In the omnichannel era, when people engage in a shopping process their preferred method of information is e-WOM (King et al., 2014). e-WOM is defined as "any positive or negative statement made by potential, actual, or former customers about a product or company, which is made available to a multitude of people and institutions via the Internet" (Hennig-Thurau et al., 2003, p. 39). The strength of the influence of e-WOM on consumer behaviour is related to the quality of the posted message. e-WOM quality is defined as the relevance and usefulness of e-WOM based on the information content, the strength, and accuracy of the argument (Awad and Ragowsky, 2008). Cheung and Thadani (2012) conclude that the literature on the consequences of e-WOM is fragmented and has mostly focussed on attitudes and purchase intention (e.g. Hong-Youl et al., 2016) and, thus, encourage research involving other response variables. In this line, See-To and Ho (2014) acknowledge the lack of studies investigating the impact of e-WOM on value co-creation and set this as a research question in their theoretical model; they posit that reading e-WOM about a firm affects customer co-creation directly. e-WOM represents a contact with the brand that is not supplier-initiated and provides knowledge about the firm or its products and, thus, is part of the customer learning process in the conceptual model of value co-creation produced by Payne et al. (2009). By acquiring knowledge implicit in e-WOM the individual receives social support and this contributes to develop affect towards the firm, being the customer more willing to co-create (Chiu et al., 2015; Zhu et al., 2016). We also find the support for the relationship between e-WOM quality and co-creation within social exchange theory, which argues that people develop and maintain relationships with others based on the expectation that doing so will lead to rewards of some kind (Blau, 1964). This theory has been applied to explain knowledge sharing in virtual communities (Chiu et al., 2006; Liou et al., 2016) and CCB in online contexts (Anaza, 2014; Anaza and Zhao, 2013). Following the premises of social exchange theory, customers would participate in co-creation if they believe that knowledge exchange should be mutual and feel the need to reciprocate in view of the contributions of others (Chiu et al., 2006; Zwass, 2010). When a customer receives quality e-WOM they are moved by a kind of altruistic motivation to co-create as a way to correspond by doing something that will benefit others. Thus, we hypothesise:

H5. e-WOM quality positively affects CPB.

H6. e-WOM quality positively affects CCB.

\subsection{Different effects of antecedents on $C P B$ and $C C B$}

A central thesis of this paper is the different effect of the antecedent factors on CPB and CCB. The logic behind this expectation is found in the organisational behaviour literature, where the concept of OCB (Organ, 1988; Podsakoff and MacKenzie, 1997) originated. Citizenship behaviour, as discussed in Section 2.1, is extra-role or discretionary behaviour that exceeds 
task performance, or in-role behaviour. The paper of Groth (2005), which opens the research line investigating citizenship behaviours and comparing $\mathrm{CCB}$ and $\mathrm{CPB}$, analyses the different impact of antecedent variables on the two behaviours. CCB are performed at the free will of customers and therefore, should have stronger motivations that are not required for $\mathrm{CPB}$, which are in-role behaviours. As such, Groth (2005) finds that CPB are more strongly affected by socialisation or learning about the task, whereas CCB are more strongly predicted by customer satisfaction with the service. Most of the papers in this research line have focussed on $\mathrm{CCB}$, leaving aside $\mathrm{CPB}$, because of the higher relative value of $\mathrm{CCB}$ for the firm. Selecting different sets of antecedents for each of the behaviours, Yi and Gong (2013) found that role clarity, ability and motivation predict $\mathrm{CPB}$ while distributive justice predicts $\mathrm{CCB}$. In the online context, a few recent papers have analysed CCB but to the best of our knowledge, there are no studies analysing CCB and CPB simultaneously. Thus, there is limited evidence on the different strength of predictors of the two co-creation behaviours. Table II summarises the findings about the antecedents of $\mathrm{CPB}$ and $\mathrm{CCB}$ behaviours showing that there are related, although different, variables to the ones of our model.

Perceived ease-of-use of the co-creation platform, as a variable drawn from the TAM, would affect co-creation. Customers can have a varying degree of ability to use the internet to co-create and, as Groth (2005) and Yi and Gong (2013) found, socialisation or ability related to a task affects $\mathrm{CPB}$. Having enough knowledge and skills is a requirement for task performance in the coproduction of a service, as Kelley et al. (1992) demonstrated. In contrast, the literature has not found an influence of socialisation on citizenship behaviours, as the underlying altruistic motivations of $\mathrm{CCB}$ are not related to having specific knowledge. In particular, perceived ease-of-use of the online platform facilitates the online task of co-creation and thus, will influence $\mathrm{CPB}$ more strongly than $\mathrm{CCB}$ :

H7. The effect of perceived ease-of-use is stronger for CPB than for CCB.

Social exchange theory, which has been frequently used to explain OCB (Podsakoff et al., 2014), can also be used to explain the different strength of antecedents. Social exchanges are based on trust and other attributions that characterise people's feelings about the exchange partners (Konovsky and Pugh, 1994). Following the definitions of CCB and CPB, CCB would account for social exchange to a greater extent than CPB; thus, CCB needs to a greater extent of trust and commitment (Anaza and Zhao, 2013; Bove et al., 2009). When a customer is more product involved, the affective reaction towards the products and the firm is higher (Nambisan and Baron, 2007), and affect is characteristic of CCB. Thus, we believe fashion involvement will predict $\mathrm{CCB}$ to a greater extent than $\mathrm{CPB}$ :

H8. The effect of fashion involvement is stronger for CCB than for CPB.

\begin{tabular}{lll}
\hline & Antecedents of CPB & Antecedents of CCB \\
\hline Offline & Socialisation/learning (Groth, 2005) & Socialisation/learning (Groth, 2005) \\
context & $\begin{array}{l}\text { Role clarity (Yi and Gong, 2013) } \\
\text { Ability (Yi and Gong, 2013) }\end{array}$ & $\begin{array}{l}\text { Satisfaction (Groth, 2005) } \\
\text { Distributive justice (Yi and Gong, 2013) }\end{array}$ \\
& Motivation (Yi and Gong, 2013) & \\
Online & Customer interactions in the platform-product & Satisfaction (Anaza, 2014; Zhu et al., 2016) \\
context & content, member identity, interactivity & Commitment (Anaza and Zhao, 2013) \\
& (Nambisan and Baron, 2009) & Loyalty (Anaza and Zhao, 2013) \\
& Customer benefits-learning, social, personal, & Facilitating conditions (Anaza and Zhao, 2013) \\
& hedonic (Nambisan and Baron, 2009) & Empathy (Anaza, 2014) \\
& Interactivity (Blasco-Arcas et al., 2014) & SNS relationship quality (Wu et al., 2017) \\
& Personalisation (Blasco-Arcas et al., 2014) & SNS identification (Wu et al., 2017) \\
& & Social support (Zhu et al., 2016)
\end{tabular}

Table II.
Antecedent factors of $\mathrm{CPB}$ and $\mathrm{CCB}$ co-creation behaviours 
The quality of the information read online about the firm - e-WOM quality - would provide the customer with more information about the firm and, thus, could impact on the motivation and learning that drive CPB (Groth, 2005; Yi and Gong, 2013). As well, by reading quality e-WOM consumers receive social support from others (Zhu et al., 2016), and their trust in the firm and its products increases (Awad and Ragowsky, 2008). Social support, which encompasses informational and emotional support, brings good mood and satisfaction towards the firm (Chiu et al., 2015), and thus, based on social exchange theory, would contribute to a context in which $\mathrm{CCB}$ are likely to appear. Therefore, reading quality e-WOM would affect positively both co-creation behaviours but as it contributes to build a closer customer-firm relationship, it would predict discretionary behaviour (CCB), to a greater extent than task performance behaviour (CPB):

H9. The effect of e-WOM quality is stronger for $\mathrm{CCB}$ than for $\mathrm{CPB}$.

\subsection{Consequences of online co-creation behaviours}

We suggest that the outcomes of $\mathrm{CPB}$ and $\mathrm{CCB}$ are engagement and intention to continue co-creating, mediated by satisfaction with co-creation. Although Payne et al. (2009) do not include consequences of value co-creation in their model, they argue that firms design specific co-creation encounters with the aim of delighting customers, thus, providing enhancement and offering further opportunities to co-create.

There is scant research investigating the consequences of co-creation activities; however, there is some evidence suggesting that co-creation of value with a firm is related both to customer satisfaction (Ennew and Binks, 1999; Mathis et al., 2016) and to approach behaviours that contribute to the creation of stronger bonds between the customer and the brand (Cossío-Silva et al., 2016; Grissemann and Stokburger-Sauer, 2012). By participating in co-creation activities, it is likely that customer satisfaction increases as the customer feels that his/her needs and desires will be met more closely by the firm (Zeithaml et al., 2006). The literature has also hypothesised the opposite direction of causality, where satisfaction affects co-creation (e.g. Anaza and Zhao, 2013; Groth, 2005; Zhu et al., 2016); however, Groth (2005) highlights as limitation of his research and a future research line that the direction of causality could be from co-creation to satisfaction. Nysveen and Pedersen (2014) demonstrate the direct and indirect effects of co-creation on satisfaction, on the reasoning that customer co-creation builds up the customer-firm relationship, but they also point out that this could be a dynamic or iterative process where satisfaction over time would influence customer's co-creation. Our model suggests that a higher level of co-creation translates into greater satisfaction with the co-creation experience, which is a different construct to customer satisfaction with the firm. It is related to the concept of decision satisfaction, which argues that customers experience satisfaction not only with the product or service purchased but also with the purchase process (Heitmann et al., 2007). Satisfaction here refers to an individual's satisfaction with his or her own co-creation performance. If a company succeeds in involving customers in collaboration activities that enhance the customer's feelings of being part of a community, positive perceptions and actions can be expected (Grissemann and Stokburger-Sauer, 2012). More specifically, in their study of co-creation experience in service recovery, Dong et al. (2008) confirmed that as the level of co-creation increases customers evaluate their own participation more positively and show greater satisfaction regarding the recovery outcomes. We can extend these arguments and findings to the virtual co-creation context and, thus, hypothesise that when the level of co-creation is higher, satisfaction with the co-creation process increases:

H10. CPB positively affects satisfaction with co-creation.

H11. CCB positively affects satisfaction with co-creation. 
Our model suggests that customer engagement is a positive consequence of co-creation. Customer engagement has emerged as a very rich variable in understanding the building of quality relationships between firms and consumers (Harmeling et al., 2017). Hollebeek (2011, p. 6) defines customer brand engagement as "the level of a customer's motivational, brand-related, and context-dependent state of mind characterised by specific levels of cognitive, emotional, and behavioural activity in brand interactions". The construct of customer engagement overcomes the limitations of traditional variables such as satisfaction or service quality, allowing us to understand consumer behaviour in the light of the theories of value co-creation (Brodie et al., 2011; Vivek et al., 2012). This is due to the fact that unlike other relational marketing constructs, engagement is related to interactive experiences and value co-creation (Brodie et al., 2011), involves an active relationship with the brand (Mollen and Wilson, 2010), and creates emotional bonds (Wang, 2006). Brodie et al. (2011) differentiate the construct of customer engagement from other related constructs such as involvement by building its nomological network, concluding that participation and involvement are necessary antecedents of customer engagement. Trying to ascertain the role of engagement in online experiences, Mollen and Wilson (2010, p. 923) define online engagement as "a cognitive and affective commitment to an active relationship with the brand as personified by the website or other computer-mediated entities designed to communicate brand value”. In a later paper, Brodie et al. (2013) explore customer engagement in virtual brand communities and suggest that by interacting in brand-related blogs or providing online feedback to firms customer engagement is generated in a dynamic and iterative process. Recent research on customer engagement marketing has emphasised the role of online value co-creation as engagement initiatives (Harmeling et al., 2017). In this line, Dessart et al. (2015), based on qualitative research, have built a conceptual framework to understand customer engagement within online brand communities and identify customer satisfaction with the brand as a driver of engagement. Furthermore, Ramaswamy and Ozcan's (2016) integrative conceptual framework of brand engagement platforms in value co-creation provides support for the hypothesis that a satisfactory experience of co-creation deepens customer engagement with the firm. Thus, the following hypothesis is proposed:

\section{H12. Satisfaction with co-creation positively affects engagement.}

If the experience of co-creation is satisfactory, customers will be willing to participate in future co-creation activities with the firm in line with the well-established satisfaction-loyalty link, which is also evidenced in the online context (Anderson and Srinivasan, 2003). In the offline co-creation context, Dong et al. (2008) found that when customers are satisfied with their collaboration with a company for service recovery, they are more likely to co-create with the firm in the future. Moreover, by participating in an online co-creation process, customers feel enabled and competent (Füller et al., 2009) and as a consequence they are stimulated to participate in future co-creation tasks. Hence, the following hypothesis is proposed:

H13. Satisfaction with co-creation positively affects intention to continue co-creating.

\subsection{Cross-country analysis}

Due to the different levels of information technology diffusion across countries, multi-country analysis has motivated recent research (e.g. Zhao, 2011; Sabiote et al., 2012; Lucia-Palacios et al., 2014). The UK and Spain are examples of two countries with different levels of e-commerce penetration. In the apparel and footwear category, 18.7 per cent of sales were made on the internet in the UK in 2016 compared to just 6.6 per cent in Spain (Euromonitor International, 2017a, b). Regarding the use of SNS in 2016, 69 per cent of 
British participated in social networks while in Spain this figure was only 56 per cent (Eurostat, 2017a). On the other hand, the use of SNS by enterprises in 2016 as part of their strategy is higher in the UK (UK 52 per cent vs Spain 38 per cent of enterprises) (Eurostat, 2017b). These data seem to indicate that there may be differences in online co-creation behaviour between Spanish and British consumers.

Previous research about the cultural framework has used Hofstede's framework. National culture is seen as a group of shared significances transmitted by a series of mental programmes that control the answers in a determined context (Hofstede, 2003). The basic theory of a cognitive focus on culture is that the parameters of processing acquired in a culture persist and influence behaviour in spite of the changes in contextual circumstances. Hofstede's dimensions facilitate analysis on a national level, and they are standardised in order to allow multiple and easier comparisons between countries. Hofstede's dimensions have been used in different contexts, including information systems (Lim and Palacio-Marques, 2011; Lucia-Palacios et al., 2014). Spain and the UK occupy different positions in important cultural dimensions proposed by Hofstede (2003): power distance (Spain 57 vs UK 35); individualism (Spain 51 vs UK 89); masculinity (Spain 42 vs UK 66); and uncertainty avoidance (Spain 86 vs UK 35).

According to Chan et al. (2010), customer participation is social exchange; therefore, the norms, roles and expectations of customers would be influenced by each party's cultural background (Patterson et al., 2006). Chan et al. (2010) demonstrate that individualism-collectivism and power distance cultural value orientations moderate the effects of customer participation on value creation. The authors state that people with a higher collectivist value orientation, for instance Spain compared with UK, tend to be more expressively motivated and hope to establish social relationships. They place a higher value on the high "touch" component of their participation (Malhotra et al., 1994; Tata, 2005). Collectivist cultures are more predisposed to establishing a relationship with companies as "friends" and adapt their behaviours to cooperate and make personal connections (Stryker and Statham, 1985). On the other hand, customers with a higher individualistic value orientation prefer rewards that are proportional to their own contributions (Chen et al., 1998). They are less concerned with relationship building and more with customised service outcomes (Chan et al., 2010). According to Johansson (1990), customers with a higher power distance value orientation, for instance Spain compared with UK, may benefit less from participating in the service process. Increasing customer involvement in decision making may also generate greater anxiety (Chan et al., 2010). Therefore, we acknowledge the importance of incorporating culture into co-creation behaviour models. Although there is insufficient evidence to state a specific moderation effect on the relationships, based on Hofstede's (2003) cultural dimensions and the above discussed papers we are able to set a general moderating hypothesis:

H14. Culture moderates the relationships of antecedents and consequences of virtual customer co-creation behaviours.

In essence, if culture does indeed have an influence in the relationship of our model, then we will have to assess the impact of these effects. If culture does not moderate the causal relationships, then we will possess some evidence to support the alternative proposition that our model is culturally robust.

\section{Methodology}

\subsection{Context of the study}

The context of our study is the fashion retail sector. The fashion industry was slow to adopt digital channels due to the experiential nature of the product (Blázquez, 2014). However, recent advances have reversed the situation and fashion has become the fastest growing 
category in online retail across Europe (Euromonitor International, 2017a, b). Fashion retailers are increasingly using social media to interact and allow co-creation with the digitally savvy customer (Hamilton, 2015). Due to the recent activity on social media, little research exists in co-creation in this sector. In addition, the household consumption expenditure on clothing in both countries is markedly different. The highest expenditure on clothing in the European Union in 2016 was in the UK, with per capita spending of $€ 953$, while Spain ranked fifth with an expenditure of $€ 536$ per capita (Euromonitor International, 2017a, b).

\subsection{Sample and data collection}

This research was carried out based on an online questionnaire aimed at active online co-creators in the fashion retail sector in Spain and the UK. The survey was managed by a market research institute that had access to online panels in both countries. Gender and age quotas were set to reflect the profile of online shoppers in the sector (see Table III). The individuals were asked to answer the questions about the retailer they co-created with most recently, which they could choose from an extensive list of retailers or else write a valid name. The survey was completed during May and June 2016, and after eliminating invalid questionnaires (primarily due to writing a name that did not fit in the fashion retail category), we obtained a sample of 400 individuals in each country.

A common method bias could pose a problem for findings when both independent and outcome variables are collected from the same source, as is the case in this study. Hence, Harman's one factor test was conducted to assess whether a single latent factor accounted for all the observed variables in our study (Podsakoff et al., 2003). This test found no significant common method bias in our data set.

Likert scales of seven points were used to measure the variables $(1=$ strongly disagree; $7=$ strongly agree). As mentioned previously, the multidimensional $\mathrm{CCB}$ and $\mathrm{CPB}$ scales were taken from Yi and Gong (2013) and the other scales have already been employed in the literature on the internet and/or co-creation, ensuring the content validity (see the Appendix).

In order to be able to analyse the model proposed in Spain and in the UK and to study the moderator effect of culture and the mediator effect of satisfaction with co-creation on the proposed causal relationships, a multi-group structural equation model (SEM) was used, taking into consideration one of the dominant focal points for analysing the multi-group data (Hair et al., 2006). An SEM model is analysed and interpreted in two stages: the assessment of the reliability and validity of the measurement model, and the assessment of the structural model. We have used SPSS v. $15^{\circledR}$ for descriptive analysis and reliability and the unidimensionality test of the scales, and EQS v.6.1 ${ }^{\circledR}$ for structural equations modelling.

\begin{tabular}{llcr}
\hline Variable & Category & Spain $(\%)$ & UK (\%) \\
\hline \multirow{2}{*}{ Age (years) } & $16-24$ & 14.75 & 16.00 \\
& $25-34$ & 20.50 & 19.25 \\
& $35-44$ & 26.50 & 18.25 \\
& $45-54$ & 21.50 & 19.25 \\
Gender & $55-64$ & 12.00 & 14.00 \\
& $65-74$ & 4.75 & 13.25 \\
Co-creation with a fashion company & Male & 50.00 & 50.00 \\
& Female & 50.00 & 50.00 \\
& Very often & 7.80 & 22.00 \\
& Rather often & 19.00 & 23.30 \\
& Sometimes & 73.30 & 54.80
\end{tabular}

Table III.

Profile of the respondents 


\subsection{Validation of the measurement scales}

As second order factors, and following Ulaga and Eggert (2005), a confirmatory factor analysis (CFA) was performed to validate the $\mathrm{CPB}$ and $\mathrm{CCB}$ constructs using the maximum likelihood method. Following this, factor scores converted the dimensions of each concept into the first order indicators of the constructs and were incorporated in this way into the final measurement model. Next, another CFA containing all the constructs in our framework was estimated. Raw data screening showed evidence of non-normal distribution (Mardia's coefficient normalised estimate for Spain $=102.39$, for the UK $=112.96$ ), which recommended robust statistics (Satorra and Bentler, 2001). The results of the final CFA suggest that our measurement model provides a good fit to the data on the basis of a number of fit statistics (Hair et al., 2006). Moreover, the reliability of the constructs demonstrates the high-internal consistency of the constructs. Cronbach's $\alpha$ and composite reliability exceeded the recommendation of 0.70 and average variance extracted values were greater than 0.50 (Fornell and Larcker, 1981). Convergent validity has been verified by analysing the factor loadings (higher than 0.6) and their significance (Hair et al., 2006), while discriminant validity was verified using the criterion of the confidence intervals of the correlations between constructs (Anderson and Gerbing, 1988), which assure no multicollinearity problems (see the Appendix for CFA results).

\subsection{Measurement invariance analysis}

Once the validity and reliability of the scales was confirmed, we had to assure the measurement invariance of the measurement instrument in order to compare the two groups (Hair et al., 2006). In our case, the differences that exist between the ratings given by the scales in Spain and in the UK could either be the result of real differences between the countries or due to systematic errors produced by the manner in which persons in different countries respond to certain items.

In order to analyse the invariance of the measurement instrument, we followed three steps that correspond to the three invariance levels that must be complied with. The first step is to provide evidence of a good single group solution. The CFA fit was good for both samples (summarised in Table IV in the rows of single group solutions). The following step is to check that the factorial structure (number of factors) is the same in the two samples, which is called configurational invariance. This test is very similar to the previous one, the difference being that instead of estimating the model of each sample separately a multigroup estimation takes place. We checked that the $\chi^{2}$ and the degrees of freedom were the sum of the two previous ones and, while they were still significant, the remaining robust indicators indicated that it was more than reasonable to assume the same factorial structure in the two samples (root mean square error of approximation (RMSEA) $=0.04$; confirmatory fit index $(\mathrm{CFI})=0.97$; non-normed fit index $(\mathrm{NNFI})=0.97)$. The last step is to check the

Table IV.

Measurement invariance test

\begin{tabular}{|c|c|c|c|c|c|c|c|c|c|}
\hline Model & $\mathrm{S}-\mathrm{B} \chi^{2}$ & $\chi^{2 \mathrm{a}}$ & df & Dif. S-B $\chi^{2 b}$ & $\Delta \mathrm{df}$ & $p$ & RMSEA & CFI & NNFI \\
\hline \multicolumn{10}{|l|}{ Single group solution } \\
\hline Spain $(n=400)$ & $651.37^{*}$ & $961.46^{*}$ & 436 & & & & 0.03 & 0.97 & 0.97 \\
\hline UK $(n=400)$ & $661.15^{*}$ & $1,119.43^{*}$ & 436 & & & & 0.04 & 0.98 & 0.97 \\
\hline \multicolumn{10}{|c|}{ Measurement invariance $(n=800)$} \\
\hline Equal form & $1,313.24^{*}$ & $2,080.92 *$ & 872 & & & & 0.04 & 0.97 & 0.97 \\
\hline Equal factor loadings & $1,364.37 *$ & $2,147.05^{*}$ & 904 & 51.90 & 32 & 0.01 & 0.04 & 0.97 & 0.97 \\
\hline
\end{tabular}

Notes: df, degrees of freedom; Dif., difference of; RMSEA, root mean square error of approximation; CFI,

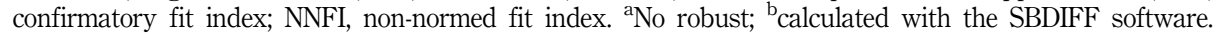
$* p<0.01$ 
invariance of the factorial loadings, which implies that it would be reasonable to assume that in the two samples the factorial loadings that join each factor with its indicator are identical. We used the SBDIFF software developed by Crawford and Henry (2003) to compare the $\chi^{2}$ of the two steps of equal form and three of equal factor loadings. Therefore, in this case, the difference of the Satorra-Bentler $\chi^{2}$ (dif. S-B $\chi^{2}$ ) was 51.90, which is significant (see Table IV). Thus, we could conclude that imposing restrictions of the equality of factorial loadings causes the fit to deteriorate significantly and, therefore, they are not plausible. In other words, we could not affirm the factorial invariance of the measurement instrument.

Nevertheless, if a partial invariance existed - if there were at least two invariable factorial loadings for each factor, we could still evaluate the moderator effect of culture on the relationships proposed (Hair et al., 2006). We found that only the restrictions corresponding to three factorial loads would improve the fit if they were eliminated. In other words, it is likely that they are different in the two samples. The other 29 loads have significances higher than 1 per cent $(p>0.01)$. Therefore, eliminating the parameter equality restriction does not improve the fit, and therefore, it is likely that they are the same in both samples. In addition, we found that the 29 loads include at least two invariable factorial loadings for each factor. In summary, we can affirm the partial invariance and proceed to evaluate the significance of the culture moderator effect in the structural relationships.

\section{Results}

\subsection{Testing of the research hypotheses and the cultural moderator effect}

Table V shows the results of our research model and the cultural moderator effect. On the one hand, we found that, in Spain, fashion involvement does not influence CPB $(p>0.10)$ significantly, whereas in the UK, this relationship is significant $(p<0.01)$. The rest of the model is quite similar in both countries and supports the proposed relationships (H1-H6 and H1O-H13) because the rejection of the hypotheses cannot be confirmed.

\begin{tabular}{|c|c|c|c|c|c|c|c|}
\hline Hypotheses & Path & $\begin{array}{c}\text { Spain } \\
\text { Standardised path } \\
\text { coefficients }\end{array}$ & $\begin{array}{l}\text { Robust } \\
t \text {-value }\end{array}$ & $\begin{array}{c}\text { UK } \\
\begin{array}{c}\text { Standardised path } \\
\text { coefficients }\end{array}\end{array}$ & $\begin{array}{l}\text { Robust } \\
t \text {-value }\end{array}$ & $\begin{array}{l}\text { Culture } \\
\text { moderat } \\
\text { effect } \\
\Delta \chi^{2} \\
(\Delta \mathrm{df}=1)\end{array}$ & or \\
\hline$H 1$ & $\mathrm{FI} \rightarrow \mathrm{CPB}$ & $0.02^{\mathrm{ns}}$ & 0.40 & $0.16^{* * * *}$ & 2.59 & $3.85^{* * *}$ & 0.04 \\
\hline H2 & $\mathrm{FI} \rightarrow \mathrm{CCB}$ & $0.10^{*}$ & 1.87 & $0.24^{* * * *}$ & 3.37 & $2.15^{\mathrm{ns}}$ & 0.14 \\
\hline H3 & $\mathrm{EOU} \rightarrow \mathrm{CPB}$ & $0.43^{* * * *}$ & 5.45 & $0.39 * * *$ & 4.77 & $0.07^{\mathrm{ns}}$ & 0.80 \\
\hline H4 & $\mathrm{EOU} \rightarrow \mathrm{CCB}$ & $0.32 * * *$ & 3.90 & $0.26^{* * * *}$ & 3.16 & $0.13^{\text {ns }}$ & 0.72 \\
\hline H5 & $\mathrm{EWOM} \rightarrow \mathrm{CPB}$ & $0.19 * *$ & 2.61 & $0.32 * * *$ & 3.54 & $1.33^{\mathrm{ns}}$ & 0.25 \\
\hline H6 & $\mathrm{EWOM} \rightarrow \mathrm{CCB}$ & $0.33^{* * * *}$ & 4.38 & $0.42^{* * *}$ & 4.36 & $0.50^{\text {ns }}$ & 0.48 \\
\hline $\mathrm{H} 1 \mathrm{O}$ & $\mathrm{CPB} \rightarrow \mathrm{SAT}$ & $0.23^{* * *}$ & 4.71 & $0.35^{* * * *}$ & 5.91 & $3.26 *$ & 0.07 \\
\hline H11 & $\mathrm{CCB} \rightarrow \mathrm{SAT}$ & $0.67 * * *$ & 10.13 & $0.65^{* * *}$ & 12.73 & $1.41^{\mathrm{ns}}$ & 0.24 \\
\hline$H 12$ & $\mathrm{SAT} \rightarrow \mathrm{ENG}$ & $0.87 * * *$ & 16.86 & $0.91 * * *$ & 14.56 & $5.45^{* * * *}$ & 0.02 \\
\hline$H 13$ & $\mathrm{SAT} \rightarrow \mathrm{IC}$ & $0.78^{* * * *}$ & 13.30 & $0.79 * * *$ & 17.47 & $0.32^{\mathrm{ns}}$ & 0.57 \\
\hline
\end{tabular}

Notes: ns, non-significant; df, degrees of freedom; FI, fashion involvement; CPB, customer participation behaviour; CCB, customer citizenship behaviour; EOU, perceived ease-of-use; EWOM, e-WOM quality; SAT, satisfaction with co-creation; ENG, engagement; IC, intention to continue co-creating. Spain: $R^{2}(\mathrm{CPB})=0.33$; $R^{2}(\mathrm{CCB})=0.39 ; R^{2}(\mathrm{SAT})=0.61 ; R^{2}(\mathrm{ENG})=0.75 ; R^{2}(\mathrm{IC})=0.60$. Goodness of fit indices: $\chi^{2}(451 \mathrm{df})=1,190.92 ;$ $\mathrm{S}-\mathrm{B} \chi^{2} \quad(451 \mathrm{df})=805.55 ; \mathrm{S}-\mathrm{B} \chi^{2} / \mathrm{df}=1.79 ; \mathrm{NFI}=0.90 ; \mathrm{NNFI}=0.95 ; \mathrm{CFI}=0.95 ; \mathrm{RMSEA}=0.04 ; \mathrm{UK}: R^{2}$ $(\mathrm{CPB})=0.56 ; R^{2}(\mathrm{CCB})=0.62 ; R^{2}(\mathrm{SAT})=0.81 ; R^{2}(\mathrm{ENG})=0.83 ; R^{2}(\mathrm{IC})=0.63$. Goodness of fit indices: $\chi^{2}$ $(451 \mathrm{df})=1,427.82 ; \mathrm{S}-\mathrm{B} \chi^{2}(451 \mathrm{df})=849.02 ; \mathrm{S}-\mathrm{B} \chi^{2} / \mathrm{df}=1.88 ; \mathrm{NFI}=0.92 ; \mathrm{NNFI}=0.95 ; \mathrm{CFI}=0.96$; RMEA $=$ 0.05. *p $<0.1 ; * * p<0.05 ; * * * p<0.01$

Table V. Hypotheses testing 
In addition, we have demonstrated that the effect of perceived ease-of-use is stronger for $\mathrm{CPB}$ than for $\mathrm{CCB}(H 7)$, the effect of fashion involvement is stronger for $\mathrm{CCB}$ than for $\mathrm{CPB}$ (H8) and the effect of e-WOM quality is stronger for CCB than for CPB (H9), since standardised factor loadings are higher in the two considered countries.

On the other hand, the multi-group model in which we have added the structural part provided a good fit to the data $\left(\chi^{2}(\mathrm{df}=926)=2,658.01 ; \mathrm{S}-\mathrm{B} \chi^{2}(\mathrm{df}=926)=1,692.07\right.$ $\left.(p=0.00) ; \mathrm{S}-\mathrm{B} \chi^{2} / \mathrm{df}=1.83 ; \mathrm{RMSEA}=0.05 ; \mathrm{NFI}=0.90 ; \mathrm{CFI}=0.95 ; \mathrm{NNFI}=0.95\right)$. This will be taken as a reference for comparing the fit with the models with the restrictions of interest, which refer to the equal relationship between factors, in order to analyse whether that difference is significant and also its moderator effect.

Thus, we have compared the multi-group model without restriction with each of the 11 models with restrictions. The difference is only significant for $H 1 \quad(p<0.05), H 12$ $(p<0.01)$ and $H 10$ (albeit $p<0.1)$, which means that the adjustment becomes significantly worse when a restriction with equal parameters is added. As a consequence, there is no sense in considering these restrictions and we can conclude that the parameters are significantly different, which confirms the existence of a culture moderator effect between the relationship of fashion involvement and $\mathrm{CPB}(\mathrm{H1}), \mathrm{CPB}$ and satisfaction with co-creation (H1O) and satisfaction with co-creation and engagement (H12). These relationships are stronger in the case of the UK. This confirms H14, which is related to the culture moderating the relationships of the model.

\subsection{The mediation effect of satisfaction with co-creation}

To validate the mediator role of satisfaction with co-creation in our research model, we tested the direct effect of $\mathrm{CPB}$ and $\mathrm{CCB}$ on engagement and intention to continue co-creating; subsequently, the direct effect model was compared with its respective simple mediation model, providing the size effect $\left(f^{2}\right)$ of the $R^{2}$ variation (Cohen, 1988). The results of the mediation effects are shown in Table VI. For Spain, the data confirm a full mediation effect of satisfaction with co-creation in the relationships between $\mathrm{CPB}$ on engagement and the intention to continue co-creation as the effect is strong (the $f^{2}$ value is higher than 0.35 ). However, there is a partial mediation effect of satisfaction with co-creation in the relationships between $\mathrm{CCB}$ on engagement and intention to continue co-creation with a moderate result (the $f^{2}$ value is higher than 0.15 but lower than 0.5 ). In the case of the UK, the data confirm a strong full mediation effect of satisfaction with co-creation in the relationships between $\mathrm{CPB}$ on engagement and a medium partial mediation of satisfaction with co-creation in the relationships between $\mathrm{CPB}$ on the intention to continue co-creation and $\mathrm{CCB}$ on engagement. In the UK, there is no mediation effect of satisfaction with co-creation in the relationship between $\mathrm{CCB}$ on intention to continue co-creating.

\section{Discussion}

This study aimed to understand co-creation in the virtual environment of fashion retailers by testing a model of the antecedents and consequences of two types of co-creation behaviour - CPB and CCB - in two different countries, Spain and the UK. The results provide support for all the hypotheses in the UK, while in Spain the first hypothesis cannot be accepted.

Looking at the antecedents of co-creation, we found that perceived ease-of-use is a significant variable to explain co-creation behaviours in both countries (H3 and H4). We note that the influence of ease-of-use is stronger in CPB in comparison to CCB. This would imply that perceived ease-of-use works more as a necessary condition to perform the required co-creation as opposed to a stimulus to make an extra effort in the co-creation task. This finding confirming $H 7$ is in line with previous findings whereby $\mathrm{CPB}$ is explained by socialisation or learning about the task (Groth, 2005), role clarity and ability (Yi and Gong, 2013). 


\begin{tabular}{|c|c|c|c|c|c|c|c|}
\hline & \multicolumn{2}{|c|}{ Direct model } & $\beta$ & \multicolumn{3}{|c|}{ Mediation model } & Mediation \\
\hline $\mathrm{CPB} \rightarrow \mathrm{ENG}$ & $0.55^{* * *} / 0.75^{* * * *}$ & $0.30 / 0.56$ & $\begin{array}{l}0.01^{\mathrm{ns} /} \\
0.12^{\mathrm{ns}}\end{array}$ & $0.54^{* * * * / 0.63^{* * *}}$ & $0.74 / 0.78$ & $0.59 / 0.29$ & Full/Full \\
\hline $\mathrm{CPB} \rightarrow \mathrm{SAT}$ & & & $\begin{array}{c}0.64^{* * *} \\
0.793^{* * *}\end{array}$ & & & & \\
\hline $\mathrm{SAT} \rightarrow \mathrm{ENG}$ & & & $\begin{array}{c}0.86^{* * *} / \\
0.79^{* * * *}\end{array}$ & & & & \\
\hline $\mathrm{CPB} \rightarrow \mathrm{IC}$ & $0.59 * * * / 0.62 * * *$ & $0.35 / 0.38$ & $\begin{array}{l}0.08^{\text {ns }} / \\
0.27^{* * * *}\end{array}$ & $0.46^{* * *} / 0.43^{* * *}$ & $0.60 / 0.59$ & $0.42 / 0.36$ & Full/partial \\
\hline $\mathrm{CPB} \rightarrow \mathrm{SAT}$ & & & $\begin{array}{l}0.64^{* * * *} \\
0.80^{* * * *}\end{array}$ & & & & \\
\hline $\mathrm{SAT} \rightarrow \mathrm{IC}$ & & & $\begin{array}{l}0.72^{* * * /} \\
0.54 * * *\end{array}$ & & & & \\
\hline $\mathrm{CCB} \rightarrow \mathrm{ENG}$ & $0.79 * * * / 0.56^{* * *}$ & $0.62 / 0.32$ & $\begin{array}{c}0.30 * * * / \\
0.59 * * *\end{array}$ & $0.49 * * * / 0.34 * * *$ & $0.78 / 0.89$ & $0.20 / 0.64$ & Partial/partial \\
\hline $\mathrm{CCB} \rightarrow \mathrm{SAT}$ & & & $\begin{array}{c}0.76^{* * *} / \\
083^{* * * *}\end{array}$ & & & & \\
\hline $\mathrm{SAT} \rightarrow \mathrm{ENG}$ & & & $\begin{array}{l}0.64^{* * * /} \\
0.40^{* * * *}\end{array}$ & & & & \\
\hline $\mathrm{CCB} \rightarrow \mathrm{IC}$ & $0.71 * * * / 0.82^{* * * *}$ & $0.50 / 0.68$ & $\begin{array}{l}0.28^{* * * /} \\
0.66^{* * * *}\end{array}$ & $0.43^{* * *} / 0.17^{\mathrm{ns}}$ & $0.63 / 0.69$ & $0.20 / 0.02$ & Partial/No \\
\hline $\mathrm{CCB} \rightarrow \mathrm{SAT}$ & & & $\begin{array}{c}0.76^{* * *} / \\
0.83^{* * * *}\end{array}$ & & & & \\
\hline $\mathrm{SAT} \rightarrow \mathrm{IC}$ & & & $\begin{array}{c}0.56^{* * * * /} \\
0.20^{*}\end{array}$ & & & & \\
\hline
\end{tabular}

Notes: ns, non-significant; $\mathrm{CPB}$, customer participation behaviour; $\mathrm{CCB}$, customer citizenship behaviour; SAT, satisfaction with co-creation; ENG, engagement; IC, intention to continue co-creating; $\beta$, path coefficient; $R^{2}$, root mean squared error; $f^{2}$, size effect; $\beta$ ind, $\beta$ indirect effect. $* p<0.1 ; * p<0.05 ; * * * p<0.01$

Table VI.

Mediation tests (Spain/UK)

Fashion involvement, as an individual-related psychographic trait, affects $\mathrm{CCB}$ in both countries and $\mathrm{CPB}$ in the UK only (H1 and H2). Another variable explaining co-creation behaviours is e-WOM quality ( $H 5$ and $H 6$ ). The results show that when customers read quality e-WOM about a company they take part in a learning process that contributes to co-creation (Payne et al., 2009). The influence of e-WOM quality is stronger for CCB than for $\mathrm{CPB}$ (H9). This in in line with the social exchange theory and suggests that a customer would participate more and feel the need to reciprocate in online co-creation when influenced by other customers' contributions (Chiu et al., 2006). The social support received through e-WOM develops affect towards the firm (Chiu et al., 2015), which would explain why e-WOM quality impacts CCB more strongly than CPB (H9).

The results regarding the consequences section of the research model provide evidence of the benefits of customer co-creation. All the hypotheses of this part are accepted (H1O-H13), which confirms the links between the level of customer co-creation and satisfaction with co-creation, engagement and intention to continue co-creating as suggested by studies in the offline context (Dong et al., 2008). The effect of CPB on satisfaction with co-creation is significantly higher in the UK, as is the effect of satisfaction with co-creation on engagement, which means that participation satisfies and engages to British consumers to a greater extent. This could be due to the different nature and attractiveness of the co-creation tasks in the two countries. In both countries, satisfaction with co-creation fully mediates the relationship between $\mathrm{CPB}$ and engagement. The mediation of satisfaction with co-creation on intention to continue co-creating is full for Spain and partial in the UK; this means that to attain the benefits of co-creation customers not only have to participate in 
co-creation tasks but they also have to evaluate this experience as satisfactory. In the case of the mediation of satisfaction with co-creation on the relationship of $\mathrm{CCB}$ and engagement, the effect is partial in both countries. The mediation of satisfaction with co-creation on intention of future co-creation is partial in Spain and null in the UK, which suggests that British customers do not need to provide a positive evaluation of the co-creation experience in order to continue co-creating to the same extent.

Regarding the culture moderator effect in the model, we can confirm culture affects the relationship of fashion involvement and $\mathrm{CPB}(\mathrm{H1}), \mathrm{CPB}$ and satisfaction with co-creation (H1O) and satisfaction with co-creation and engagement (H12). These relationships are stronger in the case of the UK. Based on the previous research, the Hofstede's cultural dimension that could affect these relationships is power distance. Spanish customers, who have higher power distance than British customers, would enjoy to a lesser extent participating in the co-creation process (Johansson, 1990) as they perceive it as a face-losing situation because it can diminish the desired inequality between themselves and their perceived subordinates, the employees/the company (Mattila, 1999; Patterson et al., 2006). These customers tend to prefer and respect a more decisive and nonconsultative service approach (Joiner, 2001).

The non-significance of $H 1$ for Spain means that people will not increase their level of in-role participation if they are more involved in the product category. This is in line with $\mathrm{CPB}$ being required and expected behaviours that do not necessitate high involvement. This result is not really in contradiction with the theory as the literature advocates a positive influence of involvement on behaviours entailing helping others (Füller et al., 2009), such as $\mathrm{CCB}$, while $\mathrm{CPB}$ is more strongly related to having skills to perform the task (Anaza and Zhao, 2013; Yi and Gong, 2013). To explain this and also the stronger effect of e-WOM quality in the UK compared to Spain, and the weaker effect of perceived ease-of-use in the UK, we can refer to the more widespread use of digital channels for shopping in the UK. As Spanish consumers still need to get familiarised with online co-creation platforms, perceived ease-of-use is the strongest antecedent making other antecedents less relevant, while in the case of British consumers other motivations become more relevant.

Finally, our results confirm the expectation based on the literature that due to the different levels of effort required from the customer to perform each of the co-creation behaviours, they have different drivers and consequences (Yi and Gong, 2013). Although all the antecedents and consequences, with the exception of fashion involvement in Spain, are significant in both countries, the different size of the parameters referring to $\mathrm{CPB}$ and $\mathrm{CCB}$ suggests that they require different levels or types of motivator and have different outcomes in terms of customer satisfaction with co-creation, engagement and intention of future co-creation.

\section{Conclusion}

The main aim of this study was to analyse the antecedents and consequences of two types of co-creation behaviour that require a distinct degree of effort from the customer: $\mathrm{CPB}$ and $\mathrm{CCB}$ in the online environment of retailers in two different countries. Following the logic of Payne et al. (2009), our research model has contemplated three antecedents of each of co-creation behaviour: category involvement as an exponent of individual characteristics that affect customer processes, and two variables that are specific of the online context - perceived ease-of-use of the online co-creation platform and e-WOM quality - that refer to the supplier's value-creating processes and to additional sources of value co-creation, respectively.

\subsection{Theoretical contributions}

This study contributes to the research on customer value co-creation in the following aspects. First, it contributes to increasing our knowledge of the antecedents and consequences of online co-creation behaviours by extending the literature on 
co-creation in the offline context to the online context. More specifically, although the role of category involvement and e-WOM as antecedents of co-creation has been suggested as a research priority (Wu et al., 2017), it has not yet been investigated (neither online nor offline). This study has developed $\mathrm{H} 1$ and $\mathrm{H} 2$ around the research proposition of France et al. (2015, p. 855) - "High category involvement leads to greater brand co-creation" and have confirmed them in the online context. Similarly, we have followed the research proposition of See-To and Ho (2014) regarding the impact of e-WOM on co-creation in the SNS of the firm through the development and testing of $H 5$ and H6. These results, together with those referring to the role as antecedent of perceived ease-of-use of the online co-creation platform ( $\mathrm{H} 3$ and $\mathrm{H} 4$ ), contribute to our understanding of the process of value co-creation as an integration of customer processes, supplier processes and additional sources of value during customer-firm encounters according to the model of Payne et al. (2009). A second contribution of our study refers to investigating, in the online environment, two types of co-creation behaviour, $\mathrm{CPB}$ and $\mathrm{CCB}$, and comparing the antecedents of co-creation for these two behaviours. This comparison had been done in the offline context (Groth, 2005; Yi and Gong, 2013), but not in the online context. As a result, our findings add to the limited number of papers (Anaza, 2014; Anaza and Zhao, 2013; Wu et al., 2017; Zhu et al., 2016) that have investigated the antecedents of online CCB by extending the range of antecedents and comparing them for $\mathrm{CPB}$ and $\mathrm{CCB}$. Our results suggest that $\mathrm{CCB}$ are related to stronger relationships with the firm, while $\mathrm{CPB}$ are explained more strongly by the facilitating conditions of the co-creation encounter, and thus, confirm the usefulness of the social exchange theory to explain co-creation in the online context, particularly when in-role (CPB) and extra-role (CCB) behaviours are differentiated. A third contribution of the study refers to the cross-cultural validation of the relationships between $\mathrm{CPB}$ and $\mathrm{CCB}$ 's antecedents and consequences following research calls (Jaakkola et al., 2015; Yi and Gong, 2013). Our results suggest that, although co-creation is a global phenomenon, the cultural effects may moderate certain theoretical relationships in the co-creation process. A final contribution of our study is a methodological one; we have provided validation of the $\mathrm{CPB}$ and $\mathrm{CCB}$ multidimensional scales developed by Yi and Gong (2013) in an online and cross-cultural context, following the authors' explicit call to test the applicability of the scales in different countries and validate the dimensional structure of customer value co-creation across different cultures.

\subsection{Managerial implications}

This study has relevant implications for firms that are interested in developing and managing online co-creation activities with customers. The results confirm the benefits of customer value co-creation in terms of engagement with the firm, which is a particularly powerful measure of the quality of the bonds between a customer and a brand or a firm. Therefore, whilst firms are encouraged to invite customers to co-create, for example by co-designing, writing reviews, or customising products, they should also ensure that these activities are satisfactory for the customers that perform them as our research indicates that satisfaction with co-creation mediates the effects of co-creation on outcomes such as engagement and intention of future co-creation. Our results also provide managers some hints on how to stimulate co-creation behaviours. First of all, they should design a user-friendly co-creation platform as perceived ease-of-use is explicating online co-creation to a high degree; then, they should communicate how easy it is to perform co-creation online as a low perceived ease-of-use is a barrier that may be related to poor design or a lack of customer familiarity with the online co-creation task. Furthermore, if managers want to encourage $\mathrm{CCB}$, which are co-creation behaviours that provide extra value to the firm, they should identify individuals who are highly involved in the product category to invite them to participate as our research shows that fashion involvement explains discretionary 
co-creation behaviours. Additionally, managers should give incentives for customers to write online product reviews or post messages about the brand as reading such messages can encourage other customers to participate in online co-creation tasks. In addition, companies should consider the culture of the country or countries in which they intend to get users to participate in online co-creation. Firms must understand how cultural factors affect the online co-creation process and adapt their strategy, since, depending on the culture, customers give more importance to certain variables rather than others.

\subsection{Limitations and further research}

This study has some limitations relating to the research design. Our research was purposely limited to the fashion sector as this is a leading sector in the use of digital distribution and communication channels and, thus, is also a good exponent of online co-creation. Notwithstanding, future research could explore additional sectors to increase the validity of our results. Additionally, although we attempted to obtain a representative sample by establishing gender and age quotas to represent the demographic profile of the online fashion shopper, our sample was drawn from online panels, which can introduce some bias into the results as these people could be more familiar with technology and thus, more inclined to participate in online co-creation activities.

Future research could examine additional antecedents of co-creation behaviours in the online environment. Our research included three variables that capture customer processes, supplier processes and social influence, but it did not include variables referring to the relationship between the customer and the firm or brand, which could explain why people co-create with a particular firm. In addition, future research could explore the links between co-creation and purchasing behavioural variables to ascertain whether the benefits of co-creation extend not only to positive attitudes and beliefs about the firm but also to actual behaviours leading to increased sales for the company. Due to the limited attention that has been paid to the effect of culture on virtual co-creation behaviour, more cross-cultural research on this topic is needed. Future research could analyse which of Hofstede's dimensions more significantly affect the co-creation process.

\section{References}

Alden, D.L., Steenkamp, J.B.E.M. and Batra, R. (1999), "Brand positioning through advertising in Asia, North America, and Europe: the role of global consumer culture", Journal of Marketing, Vol. 63 No. 1 , pp. $75-83$.

Anaza, N. and Zhao, J. (2013), "Encounter-based antecedents of e-customer citizenship behaviors", Lournal of Services Marketing, Vol. 27 No. 2, pp. 130-140.

Anaza, N.A. (2014), "Personality antecedents of customer citizenship behaviors in online shopping situation”, Psychology \& Marketing, Vol. 31 No. 4, pp. 251-263.

Anderson, E. and Gerbing, D.W. (1988), "Structural equation modelling in practice: a review and recommended two-step approach", Psychological Bulletin, Vol. 103 No. 3, pp. 411-423.

Anderson, R.E. and Srinivasan, S.S. (2003), "E-satisfaction and e-loyalty: a contingency framework", Psychology \& Marketing, Vol. 20 No. 2, pp. 123-138.

Awad, N.F. and Ragowsky, A. (2008), "Establishing trust in electronic commerce through online word of mouth: an examination across genders", Lournal of Management Information Sustems, Vol. 24 No. 4, pp. 101-121.

Bendapudi, N. and Leone, R.P. (2003), "Psychological implications of customer participation in coproduction”, Lournal of Marketing, Vol. 67 No. 1, pp. 14-28.

Bettencourt, L.A. (1997), "Customer voluntary performance: customers as partners in service delivery", Iournal of Retailing, Vol. 73 No. 3, pp. 383-406. 
Blasco, L. (2014), "Los Procesos de Co-creación y el Engagement del Cliente. Un Análisis Empírico en Medios Interactivos", doctoral dissertation. University of Zaragoza, Zaragoza, available at: http://zaguan.unizar.es/record/13508/files/TESIS-2014-019.pdf (accessed 31 January 2017).

Blasco-Arcas, L., Hernandez-Ortega, B.I. and Jimenez-Martinez, J. (2014), "Collaborating online: the roles of interactivity and personalization", The Service Industries Iournal, Vol. 34 No. 8, pp. 677-698.

Blau, P.M. (1964), Exchange and Power in Social Life, John Wiley and Sons, New York, NY.

Blázquez, M. (2014), "Fashion shopping in multichannel retail: the role of technology in enhancing the customer experience", International Journal of Electronic Commerce, Vol. 18 No. 4, pp. 97-116.

Bloch, P.H. (1986), "The product enthusiast: implications for marketing strategy”, Lournal of Consumer Marketing, Vol. 3 No. 3, pp. 51.63.

Bove, L.L., Pervan, S.J., Beatty, S.E. and Shiu, E. (2009), "Service worker role in encouraging customer organizational citizenship behaviors", Journal of Business Research, Vol. 62 No. 7, pp. 698-705.

Brodie, R.J., Hollebeek, L.D., Jurić, B. and Ilić, A. (2011), "Customer engagement: conceptual domain, fundamental propositions, and implications for research", Lournal of Service Research, Vol. 14 No. 3, pp. 252-271.

Brodie, R.J., Ilic, A., Juric, B. and Hollebeek, L. (2013), "Consumer engagement in a virtual brand community: an exploratory analysis", Journal of Business Research, Vol. 66 No. 1, pp. 105-114.

Cano-Murillo, D.E., Kang, J. and Yoon, S. (2016), "Factors influencing prosocial consumer behavior through non-profit organizations", Internet Research, Vol. 26 No. 3, pp. 626-643.

Chan, K.W., Yim, C.K. and Lam, S.S. (2010), "Is customer participation in value creation a double-edged sword? Evidence from professional financial services across cultures", Lournal of Marketing, Vol. 74 No. 3, pp. 48-64.

Chen, C.C., Chen, X.P. and Meindl, J.R. (1998), "How can cooperation be fostered? The cultural effects of individualism-collectivism", The Academy of Management Review, Vol. 23 No. 2, pp. 285-304.

Cheung, C.M. and Thadani, D.R. (2012), "The impact of electronic word-of-mouth communication: a literature analysis and integrative model", Decision Support Svstems, Vol. 54 No. 1, pp. 461-470.

Chiu, C.M., Hsu, M.H. and Wang, E.T. (2006), "Understanding knowledge sharing in virtual communities: an integration of social capital and social cognitive theories", Decision Support Systems, Vol. 42 No. 3, pp. 1872-1888.

Chiu, C.M., Huang, H.Y., Cheng, H.L. and Sun, P.C. (2015), "Understanding online community citizenship behaviors through social support and social identity", International Iournal of Information Management, Vol. 35 No. 4, pp. 504-519.

Cohen, J. (1988), Statistical Power Analysis for the Behavioral Science, 2nd ed., Lawrence Erlbaum Associates, Hillsdale, NJ.

Constantinides, E., Brünink, L.A. and Lorenzo-Romero, L.A. (2015), "Customer motives and benefits for participating in online co-creation activities", International Journal of Internet Marketing and Advertising, Vol. 9 No. 1, pp. 21-47.

Cossío-Silva, F.J., Revilla-Camacho, M.Á., Vega-Vázquez, M. and Palacios-Florencio, B. (2016), "Value co-creation and customer loyalty", Journal of Business Research, Vol. 69 No. 5, pp. 1621-1625.

Crawford, J.R. and Henry, J.D. (2003), “The depression anxiety stress scales: normative data and latent structure in a large non-clinical sample", British Journal of Clinical Psychology, Vol. 42 No. 2, pp. 111-131.

Davis, F.D. (1989), "Perceived usefulness, perceived ease of use, and user acceptance of information technology", MIS Quarterly, Vol. 13 No. 3, pp. 319-339.

Dessart, L., Veloutsou, C. and Morgan-Thomas, A. (2015), "Consumer engagement in online brand communities: a social media perspective", Lournal of Product \& Brand Management, Vol. 24 No. 1, pp. 28-42.

Dimitriades, Z.S. (2007), "The influence of service climate and job involvement on customer-oriented organizational citizenship behavior in Greek service organizations: a survey", Emplovee Relations, Vol. 29 No. 5, pp. 469-491. 
Dong, B., Evans, K.R. and Zou, S. (2008), "The effects of customer participation in co-created service recovery", Journal of the Academy of Marketing Science, Vol. 36 No. 1, pp. 123-137.

Ennew, C.T. and Binks, M.R. (1999), "Impact of participative service relationships on quality, satisfaction and retention: An exploratory study", Journal of Business Research, Vol. 46 No. 2, pp. 121-132.

Euromonitor International (2017a), “Apparel and footwear retail in the United Kingdom”, available at: www.portal.euromonitor.com (accessed 5 February 2017).

Euromonitor International (2017b), “Apparel and footwear retail in Spain”, available at: www.portal. euromonitor.com (accessed 5 February 2017).

Eurostat (2017a), "Individuals - internet activities", available at: http://appsso.eurostat.ec.europa.eu/ nui/submitViewTableAction.do (accessed 26 April 2017).

Eurostat (2017b), "Eurostat, 2016: social media - statistics on the use by enterprises", available at: http://ec.europa.eu/eurostat/statistics-explained/index.php/Social_media_-_statistics_on_the_ use_by_enterprises (accessed 20 June 2017).

Fornell, C. and Larcker, D.F. (1981), "Evaluating structural equations models with unobservable variables and measurement error", Journal of Marketing Research, Vol. 18 No. 1, pp. 39-50.

France, C., Merrilees, B. and Miller, D. (2015), "Customer brand co-creation: a conceptual model", Marketing Intelligence \& Planning, Vol. 33 No. 6, pp. 848-864.

Füller, J., Hutter, K. and Faullant, R. (2011), "Why co-creation experience matters? Creative experience and its impact on the quantity and quality of creative contributions", R\&D Management, Vol. 41 No. 3, pp. 259-273.

Füller, J., Muhlbacher, H., Matzler, K. and Jawecki, G. (2009), "Consumer empowerment through internet-based co-creation", Iournal of Management Information Systems, Vol. 26 No. 3, pp. $71-102$.

Gebauer, J., Füller, J. and Pezzei, R. (2013), "The dark and the bright side of co-creation: triggers of member behavior in online innovation communities", Lournal of Business Research, Vol. 66 No. 9 , pp. 1516-1527.

Gefen, D., Karahanna, E. and Straub, D.W. (2003), "Trust and TAM in online shopping: an integrated model", MIS Quarterly, Vol. 27 No. 1, pp. 51-90.

Grissemann, U.S. and Stokburger-Sauer, N.E. (2012), "Customer co-creation of travel services: the role of company support and customer satisfaction with the co-creation performance", Tourism Management, Vol. 33 No. 6, pp. 1483-1492.

Groth, M. (2005), "Customers as good soldiers: examining citizenship behaviors in internet service deliveries", Journal of Management, Vol. 31 No. 1, pp. 7-27.

Hair, J.F., Black, W.C., Babin, B.J., Anderson, R.E. and Tatham, R.L. (2006), Multivariate Data Analysis, Prentice-Hall, New York, NY.

Hamilton, A. (2015), "Connecting with today's fashion retail consumers”, Retail Week Connect Reports, Retail Week, London.

Harmeling, C.M., Moffett, J.W., Arnold, M.J. and Carlson, B.D. (2017), "Toward a theory of customer engagement marketing", Journal of the Academv of Marketing Science, Vol. 45 No. 3, pp. 312-335.

Heitmann, M., Lehmann, D.R. and Herrmann, A. (2007), "Choice goal attainment and decision and consumption satisfaction", Lournal of Marketing Research, Vol. 44 No. 2, pp. 234-250.

Hennig-Thurau, T., Walsh, G. and Walsh, G. (2003), "Electronic word-of-mouth: motives for and consequences of reading customer articulations on the Internet", International Iournal of Electronic Commerce, Vol. 8 No. 2, pp. 51-74.

Hofstede, G. (2003), Culture's Consequences: Comparing Values, Behaviors, Institutions and Organizations Across Nations, Sage publications, Thousand Oaks, CA.

Hollebeek, L.D. (2011), "Demystifying customer brand engagement: exploring the loyalty nexus", Journal of Marketing Management, Vol. 27 Nos 7-8, pp. 785-807. 
Hong-Youl, H., John, J., John, J.D. and Chung, Y. (2016), "Temporal effects of information from social networks on online behavior: the role of cognitive and affective trust", Internet Research, Vol. 26 No. 1, pp. 213-235.

Jaakkola, E., Helkkula, A. and Aarikka-Stenroos, L. (2015), "Service experience co-creation: conceptualization, implications, and future research directions", Iournal of Service Management, Vol. 26 No. 2, pp. 182-205.

Johansson, J.K. (1990), "Japanese service industries and their overseas potential", Service Industries Journal, Vol. 10 No. 1, pp. 85-109.

Joiner, T.A. (2001), "The influence of national culture and organizational culture alignment on job stress and performance: evidence from Greece”, Iournal of Managerial Psychology, Vol. 16 No. 3, pp. 229-242.

Kelley, S.W., Donnelly, J.H. and Skinner, S.J. (1990), "Customer participation in service production and delivery”, Lournal of Retailing, Vol. 66 No. 3, pp. 315-335.

Kelley, S.W., Skinner, S.J. and Donnelly, J.H. (1992), “Organizational socialization of service customers”, Journal of Business Research, Vol. 25 No. 3, pp. 197-214.

King, R.A., Racherla, P. and Bush, V.D. (2014), "What we know and don't know about online word-ofmouth: a review and synthesis of the literature", Lournal of Interactive Marketing, Vol. 28 No. 3, pp. 167-183.

Konovsky, M.A. and Pugh, S.D. (1994), "Citizenship behavior and social exchange", Academv of Management Journal, Vol. 37 No. 3, pp. 656-669.

Lim, S. and Palacio-Marques, D. (2011), "Culture and purpose of Web 2.0 service adoption: a study in the USA, Korea and Spain”, The Service Industries Iournal, Vol. 31 No. 1, pp. 123-131.

Liou, D., Chih, W., Yuan, C. and Lin, C. (2016), "The study of the antecedents of knowledge sharing behavior: the empirical study of Yambol online test community", Internet Research, Vol. 26 No. 4, pp. 845-868.

Lovelock, C.H. and Young, R.F. (1979), "Look to consumers to increase productivity", Review, Vol. 57 No. 3, pp. 168-178.

Lucia-Palacios, L., Bordonaba-Juste, V., Polo-Redondo, Y. and Grünhagen, M. (2014), "E-business implementation and performance: analysis of mediating factors", Internet Research, Vol. 24 No. 2, pp. 223-245.

Malhotra, N.K., Ulgado, F.M., Agarwal, J. and Baalbaki, I. (1994), "International services marketing: a comparative evaluation of the dimensions of service quality between developed and developing countries", International Marketing Review, Vol. 11 No. 2, pp. 5-15.

Mathis, E.F., Kim, H.L., Uysal, M., Sirgy, J.M. and Prebensen, N.K. (2016), "The effect of co-creation experience on outcome variable", Annals of Tourism Research, Vol. 57, March, pp. 62-75.

Mattila, A.S. (1999), "The role of culture in the service evaluation process", Lournal of Service Research, Vol. 1 No. 3, pp. 250-261.

Mollen, A. and Wilson, H. (2010), "Engagement, telepresence and interactivity in online consumer experience: reconciling scholastic and managerial perspectives", Lournal of Business Research, Vol. 63 No. 9, pp. 919-925.

Nambisan, S. and Baron, R.A. (2007), "Interactions in virtual customer environments: implications for product support and customer relationship management", Journal of Interactive Marketing, Vol. 21 No. 2, pp. 42-62.

Nambisan, S. and Baron, R.A. (2009), "Virtual customer environments: testing a model of voluntary participation in value co-creation activities", Journal of Product Innovation Management, Vol. 26 No. 4, pp. 388-406.

Novak, T.P., Hoffman, D.L. and Yung, Y.F. (2000), "Measuring the customer experience in online environments: a structural modeling approach", Marketing Science, Vol. 19 No. 1, pp. 22-42.

Nysveen, H. and Pedersen, P.E. (2014), "Influences of co-creation on brand experience: the role of brand engagement", International Iournal of Market Research, Vol. 56 No. 6, pp. 807-832. 
O'Cass, A. (2004), "Fashion clothing consumption: antecedents and consequences of fashion clothing involvement", European Journal of Marketing, Vol. 38 No. 7, pp. 869-882.

Oliver, R. (1980), "A cognitive model of the antecedents and consequences of satisfaction decisions", Journal of Marketing Research, Vol. 17 No. 4, pp. 460-469.

Organ, D.W. (1988), Organizational Citizenship Behavior: the Good Soldier Syndrome, Lexington Books, Lexington, MA.

Ortiz, J., Chih, W. and Teng, H. (2017), "Electronic word of mouth in the Taiwanese social networking community: participation factors”, Internet Research, Vol. 27 No. 5, pp. 1058-1084.

Patterson, P.G., Cowley, E. and Prasongsukarn, K. (2006), "Service failure recovery: the moderating impact of individual-level cultural value orientation on perceptions of justice", International Journal of Research in Marketing, Vol. 23 No. 3, pp. 263-277.

Payne, A., Storbacka, K., Frow, P. and Knox, S. (2009), "Co-creating brands: diagnosing and designing the relationship experience”, Journal of Business Research, Vol. 62 No. 3, pp. 379-389.

Phang, C.W., Kankanhalli, A. and Sabherwal, R. (2009), "Usability and sociability in online communities: a comparative study of knowledge seeking and contribution", Lournal of the Association for Information Sustems, Vol. 10 No. 10, pp. 721-747.

Podsakoff, N.P., Podsakoff, P.M., MacKenzie, S.B., Maynes, T.D. and Spoelma, T.M. (2014), "Consequences of unit-level organizational citizenship behaviors: a review and recommendations for future research", Iournal of Organizational Behavior, Vol. 35 No. S1, pp. S87-S119.

Podsakoff, P.M. and MacKenzie, S.B. (1997), "Impact of organizational citizenship behavior on organizational performance: a review and suggestions for future research", Human Performance, Vol. 10 No. 2, pp. 133-151.

Podsakoff, P.M., MacKenzie, S.B., Podsakoff, N.P. and Lee, J. (2003), "Common method biases in behavioral research: a critical review of the literature and recommended remedies", Lournal of Applied Psychology, Vol. 88 No. 5, pp. 879-903.

Prahalad, C.K. and Ramaswamy, V. (2004), "Co-creation experiences: the next practice in value creation”, Lournal of Interactive Marketing, Vol. 18 No. 3, pp. 5-14.

Ramaswamy, V. and Ozcan, K. (2016), "Brand value co-creation in a digitalized world: an integrative framework and research implications", International Journal of Research in Marketing, Vol. 33 No. 1, pp. 93-106.

Rose, S., Clark, M., Samouel, P. and Hair, N. (2012), "Online customer experience in e-retailing: an empirical model of antecedents and outcomes", Lournal of Retailing, Vol. 88 No. 2, pp. 308-322.

Sabiote, C.M., Frias, D.M. and Castañeda, J.A. (2012), "E-service quality as antecedent to e-satisfaction: the moderating effect of culture", Online Information Review, Vol. 36 No. 2, pp. 157-174.

Satorra, A. and Bentler, P.M. (2001), "A scaled difference chi-square test statistic for moment structure analysis", Psychometrika, Vol. 66 No. 4, pp. 507-514.

See-To, E.W. and Ho, K.K. (2014), "Value co-creation and purchase intention in social network sites: the role of electronic word-of-mouth and trust: a theoretical analysis", Computers in Human Behavior, Vol. 31, February, pp. 182-189.

Steenkamp, J.B.E.M. and Geyskens, I. (2006), "How country characteristics affect the perceived value of a web site", Lournal of Marketing, Vol. 70 No. 3, pp. 136-150.

Steenkamp, J.B.E.M., Hofstede, F. and Wedel, M. (1999), "A cross-national investigation into the individual and national cultural antecedents of consumer innovativeness", Journal of Marketing, Vol. 63 No. 2, pp. 55-69.

Stryker, S. and Statham, A. (1985), "Symbolic interaction and role theory", in Lindzey, I.G. and Aranson, E. (Eds), Handbook of Social Psychology, Random House, New York, NY, pp. 311-378.

Tata, J. (2005), "The influence of national culture on the perceived fairness of grading procedures: a comparison of the United States and China", Iournal of Psychology, Vol. 139 No. 5, pp. 401-412. 
Teo, T.S.H., Lim, V.K.G. and Lai, R.Y.C. (1999), "Intrinsic and extrinsic motivation in internet usage", Omega. The International Iournal of Management Science, Vol. 27 No. 1, pp. 25-37.

Ulaga, W. and Eggert, A. (2005), "Relationship value in business markets: the construct and its dimensions", Lournal of Business-to-Business Marketing, Vol. 12 No. 1, pp. 73-99.

Vargo, S.L. and Lusch, R.F. (2004), "Evolving to a new dominant logic for marketing", Lournal of Marketing, Vol. 68 No. 1, pp. 1-17.

Verhoef, P.C., Kannan, P.K. and Inman, J.J. (2015), "From multi-channel retailing to Omni-channel retailing: introduction to the special issue on multi-channel retailing", Journal of Retailing, Vol. 91 No. 2, pp. 174-181.

Vivek, S.D., Beatty, S.E. and Morgan, R.M. (2012), "Customer engagement: exploring customer relationships beyond purchase", The Iournal of Marketing Theory and Practice, Vol. 20 No. 2, pp. 122-146.

Wang, A. (2006), "Advertising engagement: a driver of message involvement on message effects", Iournal of Advertising Research, Vol. 46 No. 4, pp. 355-368.

Wu, S.H., Huang, S.C.T., Tsai, C.Y.D. and Lin, P.Y. (2017), "Customer citizenship behavior on social networking sites: the role of relationship quality, identification, and service attributes", Internet Research, Vol. 27 No. 2, pp. 428-448.

Xie, C., Bagozzi, R.P. and Troye, S.V. (2008), "Trying to prosume: toward a theory of consumers as cocreators of value", Lournal of the Academy of Marketing Science, Vol. 36 No. 1, pp. 109-122.

Yi, Y. and Gong, T. (2008), "If employees 'go the extra mile', do customers reciprocate with similar behavior?”, Psychology and Marketing, Vol. 25 No. 10, pp. 961-986.

Yi, Y. and Gong, T. (2013), "Customer value co-creation behavior: scale development and validation", Journal of Business Research, Vol. 66 No. 9, pp. 1279-1284.

Yi, Y., Nataraajan, R. and Gong, T. (2011), "Customer participation and citizenship behavioral influences on employee performance, satisfaction, commitment, and turnover intention", Lournal of Business Research, Vol. 64 No. 1, pp. 87-95.

Zaichkowsky, J.L. (1994), "Research note: the personal involvement inventory: reduction, revision, and application to advertising", Journal of Advertising, Vol. 23 No. 4, pp. 59-70.

Zeithaml, V.A., Bitner, M.J. and Gremler, D.D. (2006), Services Marketing: Integrating Customer Focus Across the Firm, McGraw-Hill Companies, Boston, MA.

Zhang, M., Hu, M., Guo, M. and Liu, W. (2017), "Understanding relationships among customer experience, engagement, and word-of-mouth intention on online brand communities: the perspective of service ecosystem", Internet Research, Vol. 27 No. 4, pp. 839-857.

Zhao, F. (2011), "Impact of national culture on e-government development: a global study", Internet Research, Vol. 21 No. 3, pp. 362-380.

Zhu, D.H., Sun, H. and Chang, Y.P. (2016), "Effect of social support on customer satisfaction and citizenship behavior in online brand communities: the moderating role of support source", Journal of Retailing and Consumer Services, Vol. 31, July, pp. 287-293.

Zwass, V. (2010), "Co-creation: toward a taxonomy and an integrated research perspective", International Journal of Electronic Commerce, Vol. 15 No. 1, pp. 11-48.

(The Appendix follows overleaf.) 


\section{Appendix. Confirmatory factor analysis results}

\begin{tabular}{|c|c|c|c|c|}
\hline Indicator & $\begin{array}{c}\text { Factor } \\
\text { loading* }\end{array}$ & $\mathrm{CA}$ & $\mathrm{CR}$ & AVE \\
\hline \multicolumn{5}{|l|}{ Fashion involvement (Novak et al., 2000) } \\
\hline FI1. I consider fashion important in general & $0.90 / 0.87$ & $\begin{array}{c}0.96 / \\
0.92\end{array}$ & $\begin{array}{r}0.96 / \\
0.93\end{array}$ & $\begin{array}{c}0.84 / \\
0.73\end{array}$ \\
\hline FI2. Fashion is relevant to me & $0.94 / 0.91$ & & & \\
\hline FI3. Fashion means a lot to me & $0.93 / 0.89$ & & & \\
\hline FI4. Fashion matters to me & $0.93 / 0.92$ & & & \\
\hline FI5. Fashion is of concern to me & $0.89 / 0.65$ & & & \\
\hline \multicolumn{5}{|l|}{ Perceived ease-of-use (Teo et al., 1999) } \\
\hline $\begin{array}{l}\text { EOU1. Learning to co-create through internet with the XYZ was easy } \\
\text { for me }\end{array}$ & $0.92 / 0.84$ & $\begin{array}{r}0.95 / \\
0.92\end{array}$ & $\begin{array}{r}0.96 / \\
0.92\end{array}$ & $\begin{array}{r}0.83 / \\
0.74\end{array}$ \\
\hline EOU2. I found it easy to use the internet to co-create with $\mathrm{XYZ}$ & $0.92 / 0.89$ & & & \\
\hline EOU3. It was easy for me to become skilful at using the internet to & $0.89 / 0.87$ & & & \\
\hline
\end{tabular}

co-create with XYZ

EOU4. To me, internet was an easy to use means to co-create with XYZ

$0.93 / 0.85$

e-WOM quality (Awad and Ragowsky, 2008)

The opinions given by other consumers on the internet about XYZ ...

EWOM1 ... were relevant to me

EWOM2 ... were very helpful

EWOM3 ... provided the information I needed

$\begin{array}{cccc}0.88 / 0.89 & 0.93 / & 0.93 / & 0.81 / \\ & 0.93 & 0.93 & 0.81 \\ 0.91 / 0.91 & & & \\ 0.90 / 0.90 & & & \\ & 0.85 / & 0.88 / & 0.65 / \\ & 0.88 & 0.89 & 0.68 \\ 0.51 / 0.65 & & & \\ 0.75 / 0.72 & 0.84 / & 0.84 / & 0.63 / \\ & 0.85 & 0.85 & 0.66\end{array}$

ISE2. I searched for information on where to get products/services of XYZ ISE3.I paid attention to how others use the products/services in XYZ

Info sharing

ISH1. I clearly explained XYZ what I wanted to do

$0.80 / 0.86$

$0.84 / 0.86$

$0.91 / 0.90$

$0.85 / 0.77$

ISH2. I gave XYZ proper information

$0.88 / 0.87$

$0.91 / \quad 0.91 / \quad 0.72 /$

ISH3. I provided necessary information so that XYZ could perform

$0.87 / 0.88$ its duties

ISH4. I answered all XYZ's product/service related questions

Responsible behaviour

$0.81 / 0.80$

$\mathrm{RB1}$. I performed all the tasks that XYZ required me during the

$0.88 / 0.85$

co-creation process

RB2. I adequately completed all the expected behaviours when

I participated in the co-creation with XYZ

RB3. I fulfilled responsibilities to XYZ when I co-created

RB4. I followed XYZ's directives or orders when I participated

Personal interaction

PI1. I was friendly to XYZ or the person who attended me when

I participated in the co-creation

PI2. I was kind to XYZ or the person who helped me during participation

PI3. I was courteous to XYZ or person who helped me during participation

PI4. I was polite to XYZ or person who helped me during participation

Table AI.

Reliability and convergent validity (Spain/UK)
PI5. I didn't act rudely with XYZ or person who helped me during participation
$0.84 / 0.89$

0.91/0.91

$0.94 / 0.94 / \quad 0.80 /$

$\begin{array}{lll}0.93 & 0.93 & 0.77\end{array}$

$0.91 / 0.85$

$0.91 / 0.85$

$0.87 / 0.87$

$0.92 / 0.85$

$0.95 / 0.89$

$0.97 / 0.91$

$0.95 / 0.87$

$0.89 / 0.78$ $\begin{array}{lllll}0.97 / & 0.97 / & 0.87 /\end{array}$

$\begin{array}{lll}0.93 & 0.93 & 0.74\end{array}$ 


\begin{tabular}{|c|c|c|c|c|}
\hline Indicator & $\begin{array}{l}\text { Factor } \\
\text { loading* }\end{array}$ & $\mathrm{CA}$ & $\mathrm{CR}$ & AVE \\
\hline -creation - CCB (customer citizenship behaviour) (Yi and Gong, 2013) & & $0.77 /$ & $0.79 /$ & 0.5 \\
\hline edb & $078 / 083$ & 0.81 & 0.82 & 0.5 \\
\hline had a useful idea c & $0.64 / 0.78$ & $0.80 /$ & $0.80 /$ & $0.57 /$ \\
\hline know & & 0.84 & 0.84 & 0.64 \\
\hline FEE2. If I received good product/servi & $0.83 / 0.85$ & & & \\
\hline $\begin{array}{l}\text { FEE3. If I experienced a problem, I let XYZ know about it } \\
\text { Advocacy }\end{array}$ & $0.78 / 0.77$ & & & \\
\hline After $m$ & $0.84 / 0.88$ & $0.91 /$ & $0.91 /$ & $0.78 /$ \\
\hline about XYZ and its product/service to others & & 0.90 & 0.90 & 0.75 \\
\hline ADV2 .... I re & $0.96 / 0.82$ & & & \\
\hline $\begin{array}{l}\text { ADV3 .... I encouraged friends and relatives to participate with } \mathrm{XYZ} \\
\text { Helping }\end{array}$ & $\begin{array}{l}0.85 / 0.81 \\
0.69 / 0.71\end{array}$ & & & \\
\hline HELP1. I assisted other consumers if they needed my help on issues related & $0.92 / 0.89$ & $0.95 /$ & $0.95 /$ & $0.82 /$ \\
\hline $\begin{array}{l}\text { to XYZ } \\
\text { HELP2. I helped other consumers if they seem to have problems in aspects }\end{array}$ & $0.95 / 0.92$ & 0.93 & 0.93 & 0.77 \\
\hline $\begin{array}{l}\text { HELP3. I taught other consumers to use correctly the product/service } \\
\text { offered by XYZ }\end{array}$ & $0.90 / 0.86$ & & & \\
\hline $\begin{array}{l}\text { HELP4. I gave advice to other consumers on issues related to XYZ } \\
\text { Tolerance }\end{array}$ & $\begin{array}{l}0.85 / \\
0.50 /\end{array}$ & & & \\
\hline you finally $b$ & $0.72 / 0.62$ & $0.87 /$ & $0.88 /$ & $0.70 /$ \\
\hline TO1 .... If the product/service was not deliver as expected, I would be & & 0.80 & 0.83 & \\
\hline
\end{tabular}
willing to put up with it

TO2 .... If XYZ made a mistake during product/service delivery, I would be $\quad 0.89 / 0.90$ willing to be patient

TO3 .... If I had to wait longer than normally expected to receive the $\quad 0.90 / 0.81$ product/service from XYZ, I would be willing to adapt

Satisfaction with co-creation (Oliver, 1980)

SAT1. I think I made the right decision performing this kind of activity $\quad 0.89 / 0.84 \quad 0.95 / \quad 0.95 / \quad 0.82 /$

SAT2. The co-creation experience with XYZ was successful $\quad 0.89 / 0.84$

$0.92 \quad 0.92 \quad 0.75$

$\begin{array}{ll}\text { SAT3. I am satisfied with the activity of online co-creation offered by XYZ } & 0.93 / 0.90 \\ \text { SAT4. I am satisfied with the way XYZ managed the online co-creation } & 0.92 / 0.89\end{array}$ activity

Engagement (Blasco, 2014)

ENG1. Co-creating with XYZ allowed me to feel valued

$0.86 / 0.90 \quad 0.92 / \quad 0.93 / \quad 0.71 /$

ENG2. XYZ is interested in me by suggesting co-creation activities $\quad 0.76 / 0.81$

$0.94 \quad 0.94 \quad 0.75$

ENG3. The experience provided me a special interaction with XYZ

$0.87 / 0.88$

ENG4. I felt identified with XYZ by the fact that they allowed me to

$0.89 / 0.89$

participate actively

ENG5. My image of XYZ has improved from the experience

$0.84 /$

Intention to continue co-creating (Blasco-Arcas et al., 2014)

IC1. Given the opportunity, I would like to collaborate with XYZ in

generating ideas for new products/services in the future

IC2. I would like to participate in defining the products/services that I would $\quad 0.92 / 0.84$

$0.95 / 0.91 \quad 0.96 / \quad 0.96 / \quad 0.88 /$

$0.92 \quad 0.92 \quad 0.79$

buy from XYZ

IC3. Given the opportunity, I would like to take an active part in any act of $\quad 0.96 / 0.83$ co-creation offered by XYZ

Notes: CA, Cronbach's $\alpha$; CR, composite reliability; AVE, average variance extracted; Goodness of fit indices: Spain: $\chi^{2}(436 \mathrm{df})=961.46 ; \mathrm{S}-\mathrm{B} \chi^{2}(436 \mathrm{df})=651.37 ; \mathrm{S}-\mathrm{B} \chi^{2} / \mathrm{df}=1.49 ; \mathrm{NFI}=0.92 ; \mathrm{NNFI}=0.97 ; \mathrm{CFI}=0.97$; RMSEA $=0.035$. UK: $\chi^{2} \quad(436$ df $)=1,119.43 ; \quad S-B \chi^{2} \quad(436$ df $)=661.15 ; \quad S-B \chi^{2} / \mathrm{df}=1.51 ; \quad \mathrm{NFI}=0.93 ;$ $\mathrm{NNFI}=0.97 ; \mathrm{CFI}=0.98 ; \mathrm{RMSEA}=0.036 ; \mathrm{XYZ}$ : text that was replaced by the name of the company/brand chosen by the interviewee. $* p<0.01$

Table AI. 


\begin{tabular}{lcccccccc}
\hline & FI & EOU & EWOM & CPB & CCB & SAT & ENG & IC \\
\hline FI & $0.84 /$ & $(0.16,0.40) /$ & $(0.12,0.38) /$ & $(0.06,0.31) /$ & $(0.15,0.39) /$ & $(0.11,0.34) /$ & $(0.11,0.35) /$ & $(0.14,0.34) /$ \\
& 0.83 & $(0.36,0.58)$ & $(0.46,0.64)$ & $(0.41,0.62)$ & $(0.49,0.69)$ & $(0.41,0.63)$ & $(0.42,0.63)$ & $(0.38,0.59)$ \\
EOU & $0.08 /$ & $0.83 / 0.74$ & $(0.55,0.74) /$ & $(0.42,0.68) /$ & $(0.41,0.66) /$ & $(0.43,0.63) /$ & $(0.35,0.57) /$ & $(0.40,0.59) /$ \\
& 0.22 & & $(0.58,0.76)$ & $(0.58,0.74)$ & $(0.51,0.73)$ & $(0.60,0.80)$ & $(0.42,0.64)$ & $(0.48,0.71)$ \\
EWOM & $0.06 /$ & $0.42 / 0.45$ & $0.81 / 0.81$ & $(0.33,0.58) /$ & $(0.43,0.66) /$ & $(0.38,0.60) /$ & $(0.38,0.59) /$ & $(0.33,0.55) /$ \\
& 0.30 & & & $(0.57,0.74)$ & $(0.62,0.82)$ & $(0.52,0.74)$ & $(0.51,0.73)$ & $(0.51,0.71)$ \\
CPB & $0.03 /$ & $0.30 / 0.44$ & $0.21 / 0.43$ & $0.65 / 0.68$ & $(0.72,0.88) /$ & $(0.52,0.74) /$ & $(0.44,0.66) /$ & $(0.43,0.65) /$ \\
& 0.26 & & & & $(0.81,0.93)$ & $(0.72,0.86)$ & $(0.66,0.83)$ & $(0.61,0.78) /$ \\
CCB & $0.07 /$ & $0.28 / 0.38$ & $0.29 / 0.52$ & $0.64 / 0.75$ & $0.50 / 0.54$ & $(0.67,0.85) /$ & $(0.70,0.86) /$ & $(0.62,0.80) /$ \\
& 0.34 & & & & & $(0.78,0.88)$ & $(0.88,0.95)$ & $(0.77,0.88)$ \\
SAT & $0.05 /$ & $0.28 / 0.48$ & $0.24 / 0.40$ & $0.40 / 0.63$ & $0.58 / 0.69$ & $0.82 / 0.75$ & $(0.82,0.91) /$ & $(0.71,0.83) /$ \\
& 0.27 & & & & & & $(0.85,0.92)$ & $(0.67,0.83)$ \\
ENG & $0.05 /$ & $0.21 / 0.28$ & $0.24 / 0.39$ & $0.30 / 0.55$ & $0.61 / 0.79$ & $0.70 / 0.74$ & $0.71 / 0.75$ & $(0.67,0.81) /$ \\
& 0.27 & & & & & & & $(0.68,0.85)$ \\
IC & $0.06 /$ & $0.24 / 0.35$ & $0.20 / 0.37$ & $0.29 / 0.48$ & $0.50 / 0.68$ & $0.60 / 0.56$ & $0.55 / 0.58$ & $0.88 / 0.79$ \\
& 0.24 & & & & & & &
\end{tabular}

Notes: FI, fashion involvement; EOU, perceived ease-of-use; EWOM, e-WOM quality; CPB, customer participation behaviour; $\mathrm{CCB}$, customer citizenship behaviour; SAT, satisfaction; ENG, engagement; IC, intention to continue co-creating; the diagonal represents the AVE, while above the diagonal de 95 per cent confidence interval for the estimated factors correlations is provided, below the diagonal, the shared variance (squared correlations) is represented; discriminant validity CPB: (ISE, ISH $)=(0.42,0.67) /(0.56,0.75)$; (ISE, RB) $=(0.45$, $0.60) /(0.49,0.71) ;(\mathrm{ISE}, \mathrm{PI})=(0.39,0.62) /(0.50,0.72) ;(\mathrm{ISH}, \mathrm{RB})=(0.79,0.91) /(0.78,0.89) ;(\mathrm{ISH}, \mathrm{PI})=(0.75,0.89) /$

Table AII.

Discriminant validity (Spain/UK)
$(0.80,0.89) ;(\mathrm{RB}, \mathrm{PI})=(0.74,0.87) /(0.74,0.86) ;$ Discriminant validity $\mathrm{CCB}:(\mathrm{FEE}, \mathrm{ADV})=(0.66,0.83) /(0.68$, $0.84) ;(\mathrm{FEE}, \mathrm{HELP})=(0.42,0.64) /(0.53,0.71) ;(\mathrm{FEE}, \mathrm{TO})=(0.29,0.52) /(0.38,0.62) ;(\mathrm{ADV}, \mathrm{HELP})=(0.54,0.71) /$ $(0.56,0.72) ;(\mathrm{ADV}, \mathrm{TO})=(0.27,0.50) /(0.40,0.63) ;(\mathrm{HELP}, \mathrm{TO})=(0.35,0.56) /(0.42,0.65)$

\section{Corresponding author}

Marta Frasquet-Deltoro can be contacted at: marta.frasquet@uv.es 